Paediatr. Paedolog. 2020 55 (Suppl 1):S1-S22 https://doi.org/10.1007/s00608-020-00789-y

○ Der/die Autor(en) 2020

\section{Christian Popow ${ }^{1,2,3} \cdot$ Susanne Ohmann ${ }^{1,3}$}

'Univ.-Klinik für Kinder- und Jugendpsychiatrie, Medizinische Universität Wien, Wien, Österreich

${ }^{2}$ Landesklinikum Mauer bei Amstetten, Amstetten, Österreich

${ }^{3}$ Österreichische Gesellschaft für Verhaltenstherapie (OeGVT), Wien, Österreich

\title{
ADHS im Kindes- und Jugendalter. Update 2020
}

Das Aufmerksamkeitsdefizit-Hyperaktivitätssyndrom (ADHS) ist eine genetisch bedingte $[21,67,111,141,233$, 319] chronische Störung, die durch ein großes Spektrum [212] von persistierenden Aufmerksamkeitsproblemen, Hyperaktivität, Impulsivität und einer Störung der Emotionsregulation [64, 68, $111,310]$ sowie verschiedenen komorbiden Problemen [222], z.B. Störung des Sozialverhaltens (SSV), dysexekutive [266], kognitive [239] und Teilleistungsprobleme, Angst- und Ticstörungen gekennzeichnet ist. Probleme betreffen nicht nur die neuronale oder intellektuelle Funktion und Leistungsfähigkeit, sondern auch das Verhalten und die familiäre und soziale Integration [128, 154]. Zwillingsstudien, genetische Linkage- und genomweite Assoziationsstudien belegen eine Heredität von etwa $72-80 \%$, davon wenigstens bei einem Drittel der Betroffenen mehrere Gene betreffend.

Nach der DSM-5-Klassifikation (314.00-2; [10]) und der ICD-11-Klassifikation (6A05.0-2; [350]) werden nach den Hauptsymptomen drei Typen unterschieden: ein unaufmerksamer, ein hyperaktiv-impulsiver und ein kombinierter Typ, der die Symptome beider Typen beinhaltet. Dabei wird der hyperaktiv-impulsive als Vorstufe des kombinierten Typs gesehen. Die häufige Kombination, ADHS mit Störung des Sozialverhaltens, wird in beiden Klassifikationssystemen zusätzlich kodiert, wobei eine leichtere, oppositionelle (DSM-5 313.81 bzw. ICD-11 6C9) und eine schwerere, dissoziale Verhaltensstörung (DSM-5 312.81,2,9 und ICD-11 6C91) unterschieden werden.
ADHS betrifft wenigstens 3-6\% aller Schulkinder [263] und bedingt auch im Erwachsenenalter schwerwiegende psychische und soziale Konsequenzen $[136,173]$. Es bestehen phänotypische Geschlechtsunterschiede: Bei Buben, die eher den impulsiv-hyperaktiven bzw. kombinierten Typ aufweisen, wird ADHS etwa 3-mal häufiger diagnostiziert als bei Mädchen, die eher den unaufmerksamen Typ zeigen. Der Hintergrund dieser Unterschiede ist unklar, methodische Einflüsse [346], Einflüsse des Y-Chromosoms und der Geschlechtshormone auf die Hirnentwicklung [194], Unterschiede im exzitatorischen Glutamatsystem [339] und geschlechtsspezifische unterschiedliche Stressverarbeitung [23] werden diskutiert. Es bestehen auch geografische Prävalenzunterschiede [297], wobei eher methodische (z.B. Unterschiede in den diagnostischen Kriterien der ICD- und DSM-Klassifikation, klinische vs. epidemiologische Stichproben) als humangenetische oder umweltbedingte Ursachen diese Unterschiede bedingen dürften. Das kombinierte Krankheitsbild, ADHS mit Störung des Sozialverhaltens, bedingt eine schlechtere Prognose [40, 186, 254]. ADHS beeinträchtigt das Familien- und das soziale Leben, Schulerfolg, Freundschaften $[128,175,220]$, Berufsaussichten und das subjektive Wohlbefinden [53], erhöht die Wahrscheinlichkeit des Auftretens von Essstörungen (Adipositas und Anorexia nervosa; [226, 232]) und verursacht intrafamiliär und volkswirtschaftlich erhebliche Kosten [48, 313, 315]. Medikamentöse Therapie bringt klare Vorteile für Lebensqualität [75, 87, 127] und Zukunftschancen und jeden- falls auch Kostenvorteile [351]. Es gibt auch assoziierte Stärken des ADHS, wie vielseitige Interessen, Energie, Ausdauer, Humor, Charme, Echtheit, Kreativität, Spontaneität, Sensibilität, Mut, Willenskraft, Gefühlsbetonung und prosoziales Verhalten [195, 206, 285].

ADHS ist behandelbar [22, 50, 60, 94, 132, 224, 244, 246]: Stimulanzien, insbesondere Methylphenidat (MPH; [74]) sowie Amphetamin und Lisdexamphetamin [124, 304], der NoradrenalinWiederaufnahmehemmer, Atomoxetin (ATX, [289]), und das $\alpha_{2}$-Rezeptorenstimulierende Guanfacin ER [Hirota14]

\begin{tabular}{|c|c|}
\hline \multicolumn{2}{|c|}{ Abkürzungen } \\
\hline$A D H D$ & $\begin{array}{l}\text { "Attention deficit hyperactivity } \\
\text { disorder" }\end{array}$ \\
\hline ADHS & $\begin{array}{l}\text { Aufmerksamkeitsdefizit-Hyperak- } \\
\text { tivitätssyndrom }\end{array}$ \\
\hline ATX & Atomoxetin \\
\hline$B M D$ & $\begin{array}{l}\text { Bipolare Störung („bipolar mood } \\
\text { disorder") }\end{array}$ \\
\hline$C D$ & $\begin{array}{l}\text { "Conduct disorder" - Störung des } \\
\text { Sozialverhaltens }\end{array}$ \\
\hline$E F$ & Exekutive Funktion(en) \\
\hline $\begin{array}{l}\text { MAO- } \\
\text { Hemm- } \\
\text { stoffe }\end{array}$ & $\begin{array}{l}\text { Monoaminooxidase-Hemmstoffe } \\
\text { (wirken antidepressiv und werden } \\
\text { wegen ihrer Nebenwirkungen im } \\
\text { Kindes- und Jugendalter nicht } \\
\text { mehr verwendet) }\end{array}$ \\
\hline$M P H$ & Methylphenidat \\
\hline$O D D$ & $\begin{array}{l}\text { "Oppositional defiant disorder", } \\
\text { Störung des Sozialverhaltens mit } \\
\text { oppositionellem, aufsässigen } \\
\text { Verhalten }\end{array}$ \\
\hline$S I$ & Sensorische Integrationsstörung \\
\hline SSV & Störung des Sozialverhaltens \\
\hline
\end{tabular}




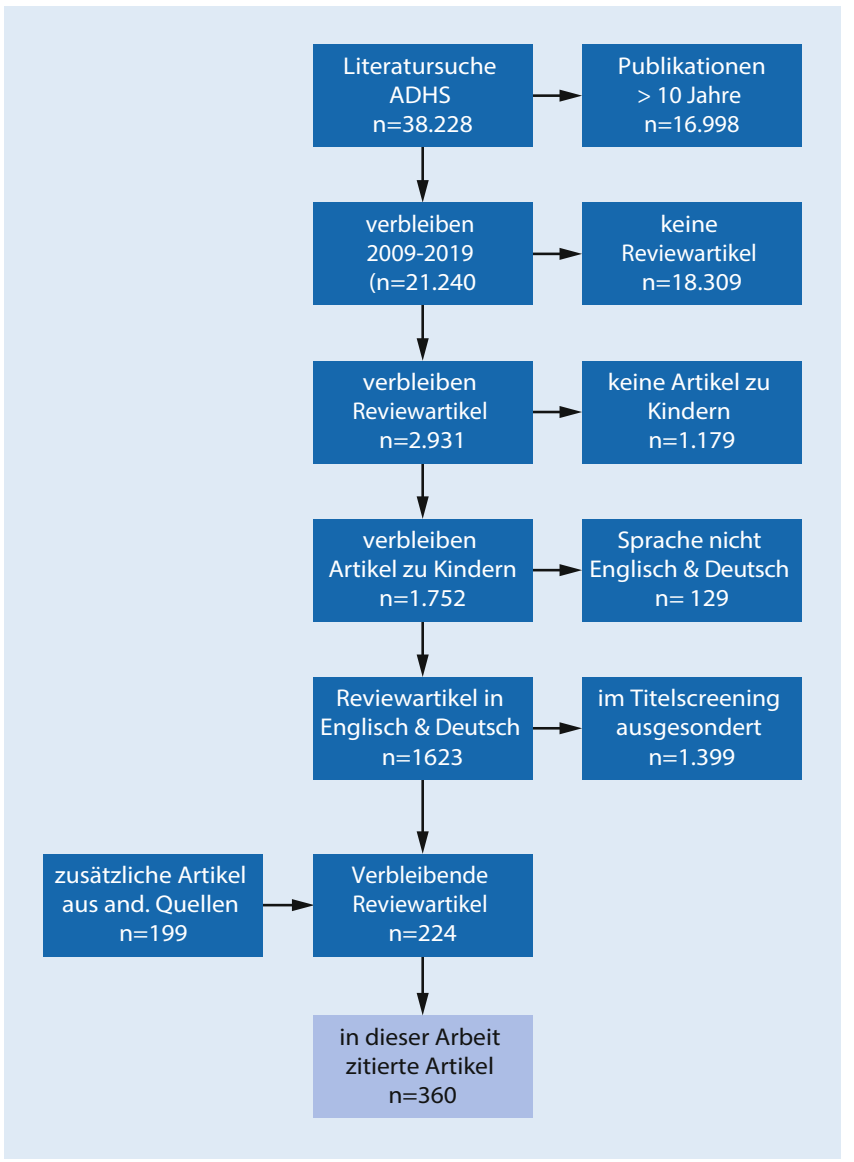

Abb. $1<$ Literatursuche und-auswahl

zeigen unterschiedliche, mittlere bis hohe Wirkstärken, allerdings auch Nebenwirkungen (Kreislaufprobleme, Appetitmangel, gelegentlich auch vermehrte Aggressivität, Schlafstörungen). Diese Medikamente sind aber in der Lage, die ADHS-Symptomatik bei etwa $80 \%$ der Kinder deutlich $\mathrm{zu}$ verbessern. Alternative medikamentöse Therapien, z.B. das $\alpha_{2}$-Sympathomimetikum Clonidin, besitzen geringere Wirkstärken oder sind wie Omega-3-Fettsäuren oder Homöopathie ineffektiv, während zusätzliche Therapien wie Psychotherapie (z.B. das Therapieprogramm für Kinder mit hyperkinetischem und oppositionellem Problemverhalten, THOP [100]), Eltern-, Teilleistungstraining, Antiaggressionsoder Ergotherapie bei entsprechender komorbider Indikation hilfreich sein können.

Die Arbeit will einen subjektiven, praxisorientierten Überblick über neuere Entwicklungen zum Thema ADHS anhand ausgewählter Literaturzitate geben.

\section{Methoden}

Die vorliegende Arbeit beruht auf einer systematischen Literaturrecherche, wobei die Datenbank PubMed nach dem Stichwort ADHD (38.228 Treffer), eingeschränkt auf die letzten 10 Jahre (21.240 Treffer), Reviewartikel (2931 Treffer), „children“ (1752 Treffer) und englische Sprache (1576 Treffer) durchsucht wurde. Die verbleibenden $1576 \mathrm{Ar}$ beiten wurden hinsichtlich ihrer Qualität, Themenrelevanz nach Titel bzw. Abstract gescreent (verbliebene Arbeiten 224) und durch zusätzliche, themenbezogen recherchierte Arbeiten $(n=199)$ ergänzt. Von diesen 423 Arbeiten wurden im vorliegenden Beitrag 360 verwendet (• Abb. 1).

\section{Ergebnisse}

\section{Ätiologie}

ADHS ist eine Spektrumstörung, d. h. es gibt eine Vielfalt klinischer Ausprä- gungen, Schweregrade, Komorbiditäten und Verläufe sowie auch eine beträchtliche ätiologische Heterogenität [228, 315] . Strukturell finden sich globale Auffälligkeiten, insbesondere verzögerte Hirnentwicklung mit kortikaler Massenreduktion vor allem im Frontalhirn, weiterhin thalamikale und zerebelläre Strukturdefizite, Vernetzungsprobleme langer Bahnen [332] sowie Mikrostrukturanomalien frontal, temporal und parietal $[7,112$, 267, 330]. Funktionelle Defizite betreffen Aktivierung und Konnektivität in diesen Arealen [125]. Überschneidungen gibt es auch mit der Autismusspektrumstörung [319].

Als ursächlich werden genetisch und epigenetisch bedingte Probleme im Katecholamin-Neurotransmitterstoffwechsel gesehen, die eine verminderte dopaminerge inhibitorische Funktion des (rechtsseitigen) präfrontalen, cingulären und temporalen Kortex sowie im Striatum bedingen [148, 174, 219, 283]. Der präfrontale Kortex ist unter anderem für exekutive (EF) und soziale Funktionen, das Cingulum für Aufmerksamkeits- und Auswahlsteuerung zuständig. Dopaminerge Neurone sind wesentlich für Motivation, Lernen, Aufrechterhalten zielorientierten Verhaltens und beim Kurzzeitgedächtnis [277], noradrenalinerge Neurone für Aktivierung und Steuerung der Aufmerksamkeit [18] verantwortlich. Zusätzlich wurden strukturelle und funktionelle Defizite im Default-Mode-Netzwerk [29] und im Glutamatsystem [160] beschrieben. Killeen et al. [172] sehen die grundlegende Pathologie in einem Energiedefizit aktiver Neurone, deren Laktatenergienachschub durch noradrenalinabhängige Gliazellen nur unzureichend funktioniert.

ADHS wird in hohem Grad (etwa $80 \%[88,135,141,319])$ polygen vererbt ${ }^{1}$ [355]. Eltern mit ADHS haben eine mehr

1 Als wesentliche Kandidatengene gelten [333] DAT1 (Dopamintransporter, 5p15.3; [133, 253]), DRD4 (Dopamin-D4-Rezeptor, 11p15.5; [110]), DRD5 (Dopaminrezeptor D5, 4p16.1-p15.3; [213]), SNAP25 (Synaptosome-associated protein of 25 kDA, 20p11-p12; [214]), Gene, die den Dopamin- und Noradrenalinmetabolismus regulieren (Tyrosinhydroxylase, 11p15.5, DOPADecarboxylase, $7 p 11$, Dopamin- $\beta$-Hydroxylase, 9q34, Catechol-0-Methyltransferase, 22q11.2, 
als 50\%ige Chance, ein Kind mit ADHS zu bekommen [109].

Es gibt aber auch klare Hinweise für umweltbedingte Risikofaktoren [6, 210]. Prä- und perinatale Faktoren (insbesondere Frühgeburtlichkeit und perinatale Komplikationen; [119, 227, 264, 288, 298]) sowie fraglich Luftverschmutzung [96, 223], Bleiexposition [54, 105] und oxidativer Stress [327]. Veränderungen des Mikrobioms[57] können ebenfalls ein ADHS (mit-)bedingen oder verstärken: Rauchen in der Schwangerschaft z. B. scheint unabhängig vom genetischen Risiko das Risiko für das Auftreten [95, $155,159]$ von ADHS und schwereren ADHS-Verlaufsformen [323] dosisabhängig zu erhöhen. Das fetale Alkoholsyndrom [92, 165] geht mit einem verminderten Wachstum präfrontaler und temporaler Bereiche einher, intrauteriner Sauerstoff- und Eisenmangel [32], Hyperbilirubinämie [303], Jodmangel und Hypothyroxinämie [328] bzw. Behandlung mit Thyroxin in der Schwangerschaft [121] beeinträchtigen möglicherweise das dopaminerge System. Temporale und frontale Hirnschäden oder Schäden am Nucleus caudatus oder an frontostriatalen Bahnen können im Rahmen von Apoplexie, Blutungen, Verletzungen oder im Gefolge von Infektionen ebenfalls ein ADHS bedingen $[153,211]$. Auch emotionale Vernachlässigung im frühen Kindesalter [360] stellt ein erhöhtes Risiko für ADHS dar, wobei das bei der untersuchten Population rumänischer Waisenkinder wahrscheinlich erhöhte genetische Risiko nicht unabhängig davon analysiert wurde. Als protektiv werden Intelligenz [265], sozioökonomische [270] und familiäre Faktoren [268] sowie Stillen [25] gesehen.

ADHS ist durch phänotypische Heterogenität gekennzeichnet, deren genauer genetischer und pathophysiologischer Hintergrund derzeit Gegenstand intensiver Forschung ist [83]. Nach Barkley [26] lassen sich die Kardinalsymptome auf exekutive Inhibitionsdefizite, Probleme des Arbeitsgedächtnisses, der

Monoaminoxidaseinhibitor $A$ und $B-, X p 11.23$ ) und Glutamat Rezeptor, ionotropic, Aspartat 2A, $16 \mathrm{p} 13$ und das Serotonintransporter-Gen [170].

Paediatr. Paedolog. 2020 · 55 (Suppl 1):S1-S22 https://doi.org/10.1007/s00608-020-00789-y (c) Der/die Autor(en) 2020

\section{Popow $\cdot$ S. Ohmann}

\section{ADHS im Kindes- und Jugendalter. Update 2020}

\section{Zusammenfassung}

Das Aufmerksamkeitsdefizit-Hyperaktivitätssyndrom (ADHS) ist eine häufige, chronische neuropsychiatrische Störung mit genetischem Hintergrund, multiplen Komorbiditäten und einem großen Spektrum an individuellen und sozialen Beeinträchtigungen. Trotz zahlreicher positiver Eigenschaften und meist erfolgreicher medikamentöser Therapie bestehen langfristige, individuelle Auffälligkeiten und Dysfunktionen und bedingen auch im Erwachsenenalter eine deutliche Beeinträchtigung der Lebensqualität. Ungelöste Probleme sind vor allem transgenerationale soziale Belastungen, schwere Verlaufsformen mit komorbider Störung des Sozialverhaltens, therapeutische Versäumnisse und Non-Compliance sowie die Frage effektiver Prävention. Der Übersichtsbeitrag versucht, die Erkenntnisse der letzten 10 Jahre zusammenzufassen und einen Einblick in die Komplexität der Bedingungen, Auswirkungen, Diagnostik und Therapie zu geben.

Schlüsselwörter

Aufmerksamkeitsdefizit-Hyperaktivitätssyndrom $\cdot$ Kinder $\cdot$ Review

\section{ADHD in Childhood and Adolescence: Update 2020}

\section{Abstract}

Attention deficit hyperactivity disorder (ADHD) is a frequently observed, chronic neuropsychiatric condition with a genetic background, multiple comorbidities, and a wide spectrum of individual and social impairments. In spite of numerous positive characteristics and mostly successful medical treatment, long-term individual problems and deficits persist and cause significant impairment of quality of life, even in adulthood. In particular, unresolved problems consist of transgenerational social burdens, unfavorable trajectories with comorbid disturbance of social behavior, therapeutic failure, and non-compliance, as well as the question of effective prevention. In this review we try to summarize important research of the last 10 years and to provide an insight into the complexity of the conditions, impact, diagnostics and therapy.

\section{Keywords}

Attention deficit hyperactivity disorder . Children · Review
Wahrnehmung [126], der Selbstregulation, der Internalisierung von Sprache sowie der Verhaltensanalyse und -synthese zurückführen, wobei experimentell eher die Inhibition geplanter Aktivitäten (Stop- oder Go-/No-go-Aufgaben) beeinträchtigt erscheint. Entscheidend sind vor allem die defizitäre Verhaltensinhibition und Probleme im Arbeitsgedächtnis [9]. Dieses Modell wurde auch wiederholt experimentell bestätigt (z. B. [348]). Ein anderes Modell [272] sieht Probleme im Belohnungssystem (Belohnungsaufschub) und damit verbundene Motivationsschwierigkeiten als Primärdefekte, die zahlreiche Folgeprobleme bedingen. Sonuga-Barke et al. [299, 301] haben aus diesen beiden Modellen ein Dual-pathway-Modell entwickelt, das funktionale und motivationale, aber auch umweltbedingte Probleme und Anpassungsvorgänge (z.B. im Rahmen der Eltern-Kind-Interaktion bzw. das Verhalten von Eltern[-teilen] mit [unbehandeltem] ADHS [235]) berücksichtigt. Sonuga-Barke und Halperin [300] versuchten aus diesem Modell heraus auch Präventionsstrategien $\mathrm{zu}$ entwickeln. Singh [297] erklärt die Vielfältigkeit des ADHS aus der Sicht eines biopsychosozialen Modells. Insgesamt scheinen sich erhöhtes genetisches und umweltbedingtes Risiko zu ergänzen: je größer die Anzahl von Risikofaktoren, desto größer auch der Ausprägungsgrad des ADHS [41] sowie die Anzahl und der Schweregrad komorbider Probleme [201]; andererseits, je größer die Anzahl an Resilienzfaktoren, desto besser die Prognose. 


\begin{tabular}{|c|c|}
\hline Lebensalter & Symptome \\
\hline \multirow[t]{3}{*}{ Säuglinge } & Regulationsprobleme \\
\hline & Motorische Unruhe, lange Schreiphasen, Fütter- und Schlafprobleme, Wutausbrüche, keine Beruhigung durch Körperkontakt \\
\hline & Entwicklungs- und Planungsprobleme, kann Gefahren nicht abschätzen \\
\hline \multirow[t]{7}{*}{ Kleinkinder } & Angetriebenheit \\
\hline & Anstrengend, ungeduldig \\
\hline & Ständig in Bewegung, bleibt nicht lange bei der Sache \\
\hline & $\begin{array}{l}\text { Wenig Ausdauer bei Gruppenaktivitäten, wenige Freundschaften, geringe Regelakzeptanz, geringe Frustrationstoleranz, Wut- } \\
\text { ausbrüche, Schlafprobleme }\end{array}$ \\
\hline & Unendliches Fragen (auch ohne wirkliches Interesse an der Antwort), Planungsprobleme, (fein-)motorische Ungeschicklichkeit \\
\hline & Schwierigkeiten beim Belohnungsaufschub, häufige Unfälle \\
\hline & Häufige Sprachentwicklungsverzögerung \\
\hline \multirow[t]{8}{*}{ Schulkinder } & Angetriebenheit \\
\hline & Motorische Unruhe, wenig Ausdauer, geringe Frustrationstoleranz geringe Regelakzeptanz , „Kasperln“ \\
\hline & Unaufmerksamkeit \\
\hline & Leicht ablenkbar, bleibt nicht bei der Sache, ständiges Chaos, verträumt, vergisst und verliert Wichtiges, Flüchtigkeitsfehler \\
\hline & Impulsivität und Probleme im Planungsverhalten Wutausbrüche \\
\hline & Erst Handeln, dann Denken, bringt sich häufig in Gefahr, komorbide Probleme \\
\hline & Teilleistungs-, feinmotorische Probleme und Störung des Sozialverhaltens, Variante abnorme Langsamkeit \\
\hline & Geringer Selbstwert, Depression, Außenseitertum \\
\hline \multirow[t]{5}{*}{ Jugendalter } & $\begin{array}{l}\text { Unaufmerksamkeit, motorische Angetriebenheit, Impulsivität, geringe Regelakzeptanz, experimentierfreudiges Verhalten, } \\
\text { Schul- und Leistungsprobleme }\end{array}$ \\
\hline & Ausgeprägt oppositionelles, teilweise aggressives, unangepasstes pubertäres Verhalten \\
\hline & Komorbide und reaktive Probleme, ängstliche und depressive Symptome \\
\hline & Selbstwertprobleme, Rückzug \\
\hline & Störung des Sozialverhaltens - delinquentes, provokantes, experimentierfreudiges Verhalten \\
\hline
\end{tabular}

Buben sind in klinischen Stichproben deutlich stärker repräsentiert (etwa 9-10:1), wobei das Prävalenzverhältnis in epidemiologischen Feldstudien 2-3:1 beträgt. Dieser Unterschied ist vermutlich bedingt durch die vermehrte Kombination ADHS mit Verhaltensauffälligkeiten bei Buben (Buben: Mädchen = 20\%: $8 \%$; [38]) und die wegen der weniger auffälligen klinischen Symptomatik (prädominant unaufmerksamer Typ) verbundene hohe Dunkelziffer bei Mädchen.

\section{Klinik und Komorbiditäten}

Die klinische Vielfalt des ADHS wird neben den Kardinalsymptomen auch beeinflusst durch das Lebensalter $([14,118$, 156, 314, 342]; - Tab. 1 und Umweltbedingungen; s. Abschn. 1).

Multiple komorbide, internalisierende und externalisierende Probleme sowie neurokognitive Defizite [239] bestimmen zusätzlich das klinische Bild. Sie sollten sorgfältig abgeklärt und in der Thera- pie berücksichtigt werden [12, 42, 326]. Nur ein Drittel der Kinder der 579 Kinder der Multimodal Treatment Study of Children with Attention Deficit Hyperactivity Disorder (MTA [297] hatte keine komorbiden Probleme. Bei den von uns ${ }^{2}$ untersuchten 500 Kindern mit ADHS [230] waren dies nur $4 \%$ ! Die häufigsten komorbiden Probleme sind dysexekutive [169]; 99,6\% im eigenen, klinischen Patientengut, SI 6-16\% [34]), Teilleistungs- (78\% im eigenen Patientengut), Wahrnehmungs- [126] und Sprachentwicklungsstörungen (7\% im eigenen Patientengut), SSV vom oppositionellen Typ (über $50 \%$ ), schwere Depression und Angststörungen (je ein Drittel) sowie Tics (11-20\%). Eine rezente Arbeit [55] zeigt eine Verbindung zwischen ADHS, emotionalem oder sexuellen Trauma und der Entwicklung von Borderline-Persönlichkeitsstörung. Einzelne Patientengruppen

\footnotetext{
2 In einer kinder- und jugendpsychiatrischen Spezialambulanz
}

haben deutlich höhere ADHS-Prävalenzen: zum Beispiel sind ADHS und Intelligenz negativ korrelliert [265], Patienten mit chronischen Ticstörungen (55\% der Kinder mit chronischen Ticstörungen haben eine komorbide ADHS-Diagnose [120], $20 \%$ der ADHS-Kinder entwickeln eine chronische Ticstörung [45]), depressive Episoden (70 \% [37]) und Patienten aus dem Autismusspektrum (etwa 36-50\%; [149]). ADHS ist ein Risikofaktor für Unfälle und Verletzungen [269], Substanzabusus [142, 258] und Medienabhängigkeit [58, 335]. Auch Essstörungen [187], Adipositas und Diabetes Typ 2 sind bei ADHS-Patienten häufiger [184]. Bei diesen Patientengruppen sind gemeinsame genetische Faktoren sehr wahrscheinlich beteiligt.

Das Herauswachsen aus dem ADHS, Symptomverlust oder Nachreifung wird in der Literatur unterschiedlich behandelt [311]. In 50-60\% persistieren wichtige Symptome, wobei sich die Hyperaktivität bei den meisten Kindern in der 
Pubertät verringert. Inwieweit die Verbesserung eher Resilienzfaktoren, einer Nachreifung neuronaler Strukturen oder einem Therapieerfolg [311] zugeschrieben werden kann, ist im Wesentlichen unklar. Langzeitstudien zeigen, dass $\mathrm{Pa}$ tienten mit komorbiden Problemen eine schlechtere Prognose haben als Patienten mit nur ADHS [39].

Die Kombination aus ADHS und SSV ist sowohl für die Lebensqualität als auch für die Prognose bedeutsam [202]. Die amerikanische Literatur und neuerdings auch die ICD-11 unterscheiden zwischen ODD („oppositional defiant disorder", oppositionelles Trotzverhalten) mit einer Komorbiditätsrate von 30 bis $50 \%$ [344] und CD („conduct disorder“, dissoziale Verhaltensstörung) mit einer Komorbiditätsrate von etwa $3 \%$ [106]. Das Komorbiditätsrisiko ist für beide Formen höher bei der hyperaktiv-impulsiven (und kombinierten) Variante des ADHS, während die aufmerksamkeitsgestörte Form eher mit Intelligenzdefiziten einhergeht ${ }^{3}$ [344]. Sowohl der Schweregrad des ADHS als auch komorbide SSV sind abhängig von psychosozialen Faktoren (z. B. elterlicher Erziehungsstil, persönliche Erfahrungen im sozialen Netzwerk; [81, 210]). Soziales Problemverhalten und Depression prädestinieren insbesondere unbehandelt für schwere Verlaufsformen, schulisches, berufliches und soziales Versagen, Außenseitertum, Risikoverhalten, Delinquenz und Drogenabhängigkeit [142, 338]. Die therapeutischen Optionen sind limitiert durch schlechteres Ansprechen auf Medikation, auch pharmakologische Incompliance und vermehrt auftretende unerwünschte Nebenwirkungen insbesondere der antiimpulsiven Neuroleptika (z. B. Gewichtszunahme, Müdigkeit). $\mathrm{Da}$ auch die familiären Hintergrundbedingungen (Armut, ADHS-Bezugspersonen, inkonsequenter, strenger und rigider Erziehungsstil) Symptomatik und Verlauf ungünstig beeinflussen, erscheint eine möglichst im frühen

\footnotetext{
${ }^{3}$ Diese Kombination, nur aufmerksamkeitsgestörtes ADHS und Intelligenzminderung, findet sich im eigenen Datensatz nicht, insbesondere auch keine Geschlechtsunterschiede in der Leistungsdiagnostik.
}

Kindesalter einsetzende multimodale Therapie, Elternberatungs- und Gruppentherapieprogramme zusätzlich zur medikamentösen Therapie, besonders wichtig [257].

Dysexekutive Probleme, d.h. Probleme der Inhibition, des Arbeitsgedächtnisses, der Aufmerksamkeitssteuerung und im Planen und Abwägen von Entscheidungsoptionen, sensorische Integrationsstörungen (Über- oder Unterempfindlichkeit bzw. Modulationsprobleme für sensorischen Input [Sehen, Hören, Gleichgewichts-, taktile und Tiefensensibilität]) sowie Teilleistungsstörungen (Probleme der Raum-Lage-Koordination, der Serialität, Lese-Rechtschreibschwäche [139] usw.) bestimmen neben den ADHS Kardinalsymptomen und den Verhaltensproblemen den schulischen und sozialen (Miss-)Erfolg. Dysexekutive Probleme wurden in den letzten Jahren intensiv mittels bildgebender Verfahren erforscht [125, 176, 343]. Klinisch scheint dem ADHS- auch ein EF-Spektrum zu entsprechen. Die einzelnen ADHS-Untertypen weisen auch unterschiedliche EF-Defizite auf: der impulsive (und kombinierte) Typ zeigt eher Inhibitionsdefizite, die aufmerksamkeitsgestörte Form eher Probleme des Arbeitsgedächtnisses [134]. Diagnostisch werden „coole“, frontoparietal gelegene Netzwerke, die für Planen, Arbeitsgedächtnis und Inhibition zuständig sind, von „heißen“, frontolimbischen Netzwerken, mit stärkerer affektiver Komponente (Belohnung, Motivation) unterschieden [354]. Dabei werden ADHS-Defizite eher den „coolen“ EF zugeschrieben. Therapieoptionen sind neben Ergotherapie zum Teil kostenintensive Onlineprogramme (z. B. Cogmed ${ }^{4}$, die vor allem für Schädeltraumapatientinnen und -patienten entwickelt wurden [183], und kognitive Verhaltenstherapie (Review z. B. [193]).

Sensorische Integrationsstörungen (Sensory Processing Disorder, SI/SPD; [295]) werden vor allem im Kleinkind- und Grundschulalter bei 6-20\% der Kinder [34] beobachtet. Sie sind die spezifische Domäne der ergotherapeutischen Diagnostik und Therapie. Die Reaktion auf

\footnotetext{
4 www.cogmed.com oder www.executive functiontraining.com/.
}

sensorische Empfindungen ist bei verschiedenen Menschen unterschiedlich in Abhängigkeit von der Art, der Intensität, der affektiven Reaktion und der Zeitdauer. Kinder mit SI-Problemen reagieren entweder auffällig/inadäquat („sensation seeking" oder inputvermeidend/ ängstlich irritiert) bzw. werden durch die gestörte Informationsverarbeitung von anderen Tätigkeiten abgelenkt. Sensorische Integrationsprobleme können (z.B. als taktile Überempfindlichkeit) auch bis in das Erwachsenenalter persistieren, genauere epidemiologische Daten fehlen allerdings. Die Differenzialdiagnose zu ADHS ist vor allem im Kleinkindalter schwierig, sodass jedenfalls Ergotherapie bei „auffälligen“ Kindern versucht werden sollte, da sich dysexekutive Probleme unter dieser Therapie verbessern. Ein Problem ist die Verfügbarkeit von krankenkassenfinanzierten Therapieplätzen und die Anerkennung der Nützlichkeit von SI-Therapie (die Diagnose SI-Störung hat es gerade nicht in die DSM-V-Klassifikation geschafft).

Depressive Störungen sind ein häufiges komorbides Problem des ADHS [91]. Epidemiologische Studien zeigen ein für Jugendliche mit ADHS bis zu 6-fach erhöhtes Risiko (Prävalenz $8 \%$ vs. 12-50\%!), an einer depressiven Störung zu erkranken [12]. Bei hospitalisierten Kindern mit ADHS hatten $36 \%$ eine Depression, $22 \%$ eine bipolare Störung, $8 \%$ eine affektive Psychose und $3 \%$ eine Dysthymie [52]. In der MTA [320] waren affektive Störungen mit etwa 3,8 \% relativ unterdiagnostiziert, im eigenen ambulanten kinder-/jugendpsychiatrischen Krankengut schätzten sich $31,6 \%$ der Kinder im DIKJ (Depressionsinventar für Kinder und Jugendliche [308]) als depressiv ein, nach klinischer Einschätzung waren es $8,6 \%$. Die Dunkelziffer ist relativ hoch, was zum Teil darauf zurückzuführen ist, dass die Symptome der Depression bei Kindern und Jugendlichen unterschiedlich im Vergleich $\mathrm{zu}$ Erwachsenen manifestieren (z.B. Ängstlichkeit, Kopf- und Bauchschmerzen, Verweigerung von Gruppenspielen, Rückschritte in der Entwicklung), wobei sich die Symptome von ADHS und Depression teilweise überlappen (Reizbarkeit, Vergesslichkeit, Ungeduld, 
verminderte Leistungsmotivation), und dass der oft gesteigerte Antrieb der Kinder- und Jugendlichen-ADHS die Symptome der Depression überlagert bzw. ein Rückzug von der Umwelt zunächst als angenehm erlebt wird. Die Langzeitfolgen (schulischer und beruflicher Misserfolg, Selbstbehandlung mit Alkohol und Drogen, Flucht in virtuelle Welten, totaler resignativer und vermeidender Rückzug, deutlich erhöhtes Selbstmordrisiko [69]) sind, abgesehen von der massiv beeinträchtigten Lebensqualität, auch volkswirtschaftlich relevant $[36,116]$. Therapeutisch ist daher die Kombination, Stimulanzien und selektive Serotonin-Wiederaufnahmehemmer, bei entsprechender Indikation durchaus sinnvoll [3].

Bipolare Störungen (BMD) erscheinen vor allem in der amerikanischen Literatur als häufige Differenzialdiagnose zu ADHS, einerseits, weil die Ähnlichkeit der Symptome von Manie und ADHS die Diagnose erschwert, andererseits, weil auch beide Erkrankungen gleichzeitig vorkommen können [70] bzw. das Risiko einer später auftretenden bipolaren Erkrankung bei präpubertären Kindern mit ADHS deutlich erhöht ist: 50\% der nachverfolgten Kinder mit ADHS entwickelten innerhalb von 10 Jahren eine bipolare Erkrankung [131]. Familienuntersuchungen [108] zeigen eine familiäre Häufung beider Erkrankungen. Diagnostisch helfen vielleicht Alter (eventuell späterer Beginn der BMD), geringere Persistenz der manischen Symptome, Stimmungsschwankungen ohne Trigger und mit langsamerer Oszillationsfrequenz und -dauer bei BMD, Grandiositätsgefühle, Ideenflucht, Hypersexualität ohne Traumaanamnese und weniger klare familiäre Belastung bei BMD [130]. Bei komorbider Diagnose wird zunächst die Stabilisierung der BMD angestrebt, da insbesondere Stimulanzien das Auftreten einer manischen Episode begünstigen können.

Komorbide Angststörungen werden bei etwa ein Viertel bis ein Drittel der Kinder mit ADHS diagnostiziert; ein Viertel der Kinder mit Angststörungen haben auch eine ADHS-Diagnose [19, 163, 203, 242]. Angst und Störung des Sozialverhaltens sind korreliert, zwei Drittel der Kinder mit Angststörungen aus der MTA hatten auch eine entsprechende SSV-Diagnose [203]. Barkley et al. [28] fanden mütterliche Medikation mit Stimulanzien als Risikofaktor für kindliche Angststörungen. Kinder mit komorbider Angststörung sprechen weniger gut auf medikamentöse Behandlung des ADHS an und zeigen mehr medikamentenassoziierte Nebenwirkungen [241]. Dies wurde in der Studie allerdings nicht bestätigt.

Ticstörungen werden bei ADHS-Kindern häufiger beobachtet: in der MTA hatten $11 \%$ der ADHS-Kinder auch komorbide Tics; komorbides ADHS wurde bei $21-54 \%$ der Kinder mit TouretteSyndrom beobachtet [242]. Stimulanzien können vorübergehend bzw. bei manchen Kindern auch dauerhaft die Häufigkeit und Schwere von Tics erhöhen [231]. Da Clonidin im Hinblick auf ADHS über geringe Wirkstärke verfügt, und ATX Tics nur selten fördert, spricht dies eventuell für eine bevorzugte Verwendung von ATX bei ADHS und komorbider Ticstörung [249].

ADHS erhöht das Risiko von frühem Substanzmissbrauch [341, 347]. Substanzmissbrauch und Alkoholkonsum werden vor allem bei unbehandeltem ADHS häufiger beobachtet [43]. Die von Eltern aufgrund von Fehlinformationen im Internet häufig geäußerten Bedenken eines erhöhten Risikos von Substanzmissbrauch und -abhängigkeit bei MPHTherapie entbehrt jeder Grundlage. Im Gegenteil, Therapie mit MPH schützt vor späterem Suchtverhalten [43]. Yule et al. [353] fanden ein erhöhtes Risiko für Substanzmissbrauch bei den Kindern von Müttern, die selbst im Jugendalter Drogen konsumierten. Erhöhte sexuelle Risikobereitschaft wurde vor allem bei Jugendlichen mit Störung des Sozialverhaltens und Substanzmissbrauch beobachtet [275]. Auch hier erscheint eine effiziente ADHS-Therapie protektiv.

\section{Diagnostik}

Umfassende, standardisierte klinische und klinisch-psychologische Diagnostik ist mit Rücksicht auf die Komplexität des Krankheitsbilds und seiner Komorbiditäten, des Aufwands der therapeutischen
Optionen und der schlechten Prognose bei inadäquater Behandlung unbedingt erforderlich [71]. Die 2017 überarbeitete Leitlinie der DGKJP 5 [94] empfiehlt im Sinn einer multiaxialen Diagnostik als Mindestkriterien die klinische Beobachtung und klinisch-psychiatrische Diagnostik auf der Grundlage einer entsprechenden (standardisierten) Eigen-, Eltern- und Fremdanamnese (z.B. Lehrerinnen und Lehrer, Kindergärtnerinnen und -gärtner usw.), auch hinsichtlich der Komorbiditäten und der Randbedingungen. Im weiteren ist eine umfassende Intelligenzdiagnostik inklusive Diagnostik von Teilleistungsstörungen, Entwicklungsdiagnostik bei Klein- und Vorschulkindern, bei Bedarf auch entsprechende klinisch pädiatrische bzw. pädiatrisch neurologische Diagnostik und Differenzialdiagnostik indiziert [306]. Eine rezente Übersichtsarbeit betont die Wichtigkeit der Validität von Symptomfragebögen [312].

$\mathrm{Zu}$ beachten sind Unterschiede in der Bewertung von ADHS-Symptomen und psychosozialen Konsequenzen zwischen Kindern, Eltern und Lehrerinnen und Lehrern [104, 152]. Übereinstimmungen ergeben sich eher in den Bereichen Lebensqualität und Gesundheit [127]. Ein weiteres Problem sind OutcomeBewertungen, die einerseits vom Testverfahren, andererseits von der subjektiven Bewertung der Untersucherin bzw. des Untersuchers abhängen [276, 334]. Computerunterstützte Continuous-Performance-Tests [145] ermöglichen eine objektivere Untersuchung der Aufmerksamkeitsleistung. Der Test of Variables of Attention (TO-VA) ${ }^{6}$ ist ein wertvolles Instrument vor allem in weniger eindeutigen Fällen und bei gut begabten Kindern. Leider ist er durch eine relativ geringe Spezifität von $70 \%$ [280] und eine relativ geringe individuelle Reproduzierbarkeit [192] gekennzeichnet, da die individuelle Leistungsfähigkeit auch von der Tagesverfassung abhängt.

In der Praxis hat sich folgende klinisch-psychologische Standarddiagnos-

\footnotetext{
5 Deutsche Gesellschaft für Kinder- und Jugendpsychiatrie und-psychotherapie.

6 Test of Variables of Attention, https://www. tovatest.com/.
} 


\begin{tabular}{|c|c|c|}
\hline Funktionsbereich & Instrumente & $\begin{array}{l}\text { Abkürzung, Alters- } \\
\text { norm, Literatur }\end{array}$ \\
\hline Basisdiagnostik & z. B. Basisdokumentation in der Psychiatrie & BADO [82] Anamnese \\
\hline \multicolumn{3}{|l|}{ Allgemeine Psychopathologie } \\
\hline Elternbeurteilung (Child Behavior Checklist) & - & $\begin{array}{l}\mathrm{CBCL} 1.5-5[4] \mathrm{CBCL} \\
4-18[199]\end{array}$ \\
\hline $\begin{array}{l}\text { Beurteilung durch Lehrerinnen und Lehrer (Teachers' } \\
\text { Report Form) }\end{array}$ & - & TRF (6-18) [199] \\
\hline $\begin{array}{l}\text { Beurteilung durch Kindergärtner und Kindergärtne- } \\
\text { rinnen (Caregiver-Teacher's Report Form) }\end{array}$ & - & C-TRF (1.5-5) [5] \\
\hline Selbstbeurteilung (Youth Self Report) & - & YSR (11-18) [199] \\
\hline \multicolumn{3}{|l|}{ ADHS-Diagnostik - standardisierte ADHS-Fragebögen } \\
\hline $\begin{array}{l}\text { Diagnostiksystem für psychische Störungen im Kin- } \\
\text { des- und Jugendalter }\end{array}$ & - & $\begin{array}{l}\text { DISYPS-KJ [97] } \\
(6-18)\end{array}$ \\
\hline $\begin{array}{l}\text { Fremdbeurteilungsbogen für Vorschulkinder mit } \\
\text { Aufmerksamkeitsdefizit-/Hyperaktivitätsstörungen }\end{array}$ & - & $\begin{array}{l}\text { FBB-ADHS-V [98] } \\
(3-6)\end{array}$ \\
\hline Conners-Skalen zu Aufmerksamkeit und Verhalten & - & $\begin{array}{l}\text { Conners }{ }^{\circledR} 3[188] \\
(6-18)\end{array}$ \\
\hline \multicolumn{3}{|c|}{ ADHS-Diagnostik - relevante Teile aus der Intelligenz- bzw. Entwicklungsdiagnostik } \\
\hline \multirow[t]{4}{*}{ Arbeitsgedächtnis } & $\begin{array}{l}\text { Subtests des Hamburg-Wechsler-Intelligenztests für Kinder, Zahlen } \\
\text { nachsprechen, Buchstaben-Zahlen-Folgen, Rechnerisches Denken }\end{array}$ & $\begin{array}{l}\text { HAWIK-IV [238] } \\
(6.0-16.11)\end{array}$ \\
\hline & $\begin{array}{l}\text { Subtest des Adaptiven Intelligenz-Diagnostikums 2, Unmittelbares } \\
\text { Reproduzieren numerisch-rückwärts }\end{array}$ & AID2 [181] (6.0-15.11) \\
\hline & $\begin{array}{l}\text { Subtests der Kaufman Assessment Battery for Children II, Wortreihe, } \\
\text { Zahlennachsprechen, Handbewegungen }\end{array}$ & $\begin{array}{l}\text { KABC-II [167] } \\
(4-18) \\
(4-18)\end{array}$ \\
\hline & Subtest des Wiener Entwicklungstests, Zahlen merken & WET (3-6) [166] \\
\hline \multirow[t]{3}{*}{ Verarbeitungsgeschwindigkeit } & $\begin{array}{l}\text { Subtests des Hamburg-Wechsler-Intelligenztests für Kinder, Zahlen- } \\
\text { Symbol-Test, Symbol-Suche, Durchstreich-Test }\end{array}$ & $\begin{array}{l}\text { HAWIK-IV [238] } \\
(6.0-16.1)\end{array}$ \\
\hline & $\begin{array}{l}\text { Subtest des Adaptiven Intelligenz-Diagnostikums 2, Kodieren und } \\
\text { Assoziieren - Kodiermenge }\end{array}$ & $\begin{array}{l}\text { AID } 2[181] \\
(6.0-15.11)\end{array}$ \\
\hline & $\begin{array}{l}\text { Subtests des Wechsler-Preschool and Primary, Scale of Intelligence- } \\
\text { III, deutsche Version, Symbole kodieren, Symbolsuche }\end{array}$ & $\begin{array}{l}\text { WPPSI-III [336] } \\
(4.0-7.2)\end{array}$ \\
\hline \multirow[t]{2}{*}{ Merk-bzw. Lernfähigkeit } & $\begin{array}{l}\text { Subtest des Adaptiven Intelligenz-Diagnostikums 2, Kodieren und } \\
\text { Assoziieren, Assoziationen }\end{array}$ & $\begin{array}{l}\text { AID } 2[181] \\
(6.0-15.11)\end{array}$ \\
\hline & $\begin{array}{l}\text { Subtests der Kaufman Assessment Battery for Children II, Atlantis } \\
\text { verzögert, Rebus, Rebus verzögert }\end{array}$ & $\begin{array}{l}\text { KABC-II [167] } \\
(4-18)\end{array}$ \\
\hline \multicolumn{3}{|l|}{ ADHS-Diagnostik - Aufmerksamkeit } \\
\hline Daueraufmerksamkeit/Vigilanz & Continuous Performance Tests, z. B. Test of Variables of Attention & $\begin{array}{l}\text { T.O.V.A. [318] } \\
\text { visuell } \geq 4 \\
\text { auditiv } \geq 6\end{array}$ \\
\hline Aufmerksamkeitsaktivierung oder -intensität & $\begin{array}{l}\text { z. B. Subtest der Testbatterie zu Aufmerksamkeitsprüfung bzw. der } \\
\text { Kinderversion: „Alertness“ }\end{array}$ & $\begin{array}{l}\text { TAP }[356] 6-18 \\
\text { KITAP [357] 6-10 }\end{array}$ \\
\hline \multirow[t]{2}{*}{ Selektive/fokussierte Aufmerksamkeit } & \multirow{2}{*}{$\begin{array}{l}\text { Subtests der Testbatterie zur Aufmerksamkeitsprüfung bzw. der } \\
\text { Farbe-Wort-Interferenztest } \\
\text { Subtest des Hamburg-Wechsler-Intelligenztests für Kinder, } \\
\text { Durchstreichtest }\end{array}$} & $\begin{array}{l}\text { TAP [356] 6-18 } \\
\text { KITAP [357] 6-10 } \\
\text { FWIT [30] 10-85 }\end{array}$ \\
\hline & & $\begin{array}{l}\text { HAWIK-IV [238] } \\
6.0-16.11\end{array}$ \\
\hline Aufmerksamkeitsverlagerung & $\begin{array}{l}\text { z. B. Subtest der Testbatterie zur Aufmerksamkeitsprüfung bzw. der } \\
\text { Kinderversion: Flexibilität }\end{array}$ & $\begin{array}{l}\text { TAP [356] 6-18 } \\
\text { KITAP [357] 6-10 }\end{array}$ \\
\hline
\end{tabular}




\begin{tabular}{l} 
Funktionsbereich \\
\hline Geteilte Aufmerksamkeit \\
ADHS-Diagnostik - Impulsivität \\
Test of Variables of Attention \\
Subtest der Testbatterie zur Aufmerksamkeitsprüfung \\
bzw. der Kinderversion „GoNogo“ \\
ADHS-Diagnostik - Hyperaktivität \\
z. B. Quantified Behavior Test Plus \\
ADHS-Diagnostik - Gedächtnis und Lernen \\
Visuelles bzw. visuell-räumliches Gedächtnis
\end{tabular}

Gedächtnis für Gesichter

Verbales Gedächtnis

Intelligenzdiagnostik - relevante Beispiele Vorschulalter

Schulalter

Teilleistungsdiagnostik

Legasthenie (1.-6. Klasse und Erwachsene)

Dyskalkulie (1.-4. Klasse)

Exekutive Funktionen (fakultativ)

Fremdbeurteilung (Eltern, LehrerInnen)

Vorschulversion: Fremdbeurteilung (Eltern, Kindergärtner und Kindergärtnerinnen)

Inhibition

Fähigkeit zur Reizunterdrückung

\section{Instrumente}

z. B. Subtest der Testbatterie zur Aufmerksamkeitsprüfung bzw. der Kinderversion: Geteilte Aufmerksamkeit

Rey-Osterrieth Complex Figure Test

Subtest des Wiener Entwicklungstests: Schatzkästchen

(Corsi-Block-Tapping-Test)

Subtest des Kognitiven Tests für das Kindergartenalter: Bildhaftes Gedächtnis

Subtests des Developmental Neurological Assessment ${ }^{\circledR}$ :

Memory for Designs und

Memory for Names-delayed

z. B. Subtest des Developmental Neurological Assessment ${ }^{\circledR}$ : Memory for Faces und Memory for Faces-delayed

Subtests des Developmental Neuro-psychological Assessment ${ }^{\circledR}$ :

Narrative Memory, Sentence Repetition; Memory for Names und Memory for Names-delayed

Subtest des Kognitiven Tests für das Kindergartenalter

Verbaler Lern- und Merkfähigkeitstest

Wechsler Preschool and Primary Scale of Intelligence-III (deutsche Version)

Kaufman Assessment Battery for Children (ab Herbst 2014 erhältlich) Snijders Oomen Non-verbaler Intelligenztest

Hamburg-Wechsler-Intelligenztest für Kinder - 4. Auflage

Adaptives Intelligenz Diagnostikum 3

Snijders-Oomen Non-verbaler Intelligenztest

z. B. Lese- und Rechtschreibtest

z. B. Testverfahren zur Dyskalkulie

Verhaltensinventar zur Beurteilung exekutiver Funktionen

Verhaltensinventar zur Beurteilung exekutiver Funktionen für das Kindergartenalter

z. B. Subtests des Developmental Neuropsychological Assessment ${ }^{\circledR}$. Statue, Inhibition

Subtest der Testbatterie zur Aufmerksamkeitsprüfung bzw. der Kinderversion: GoNogo

Test of Variables of Attention

Farbe-Wort-Interferenztest
Abkürzung, Alters-

norm, Literatur

TAP [356] 6-18

KITAP [357] 6-10

T.O.V.A. [318] $\geq 4 / 6$

TAP [356] 6-18

KITAP [357] 6-10

QbTest Plus [190] 6-60

R-CFT [293] (6-85)

WET [166] (3-6)

CORSI [281] $\geq 6$

KET-KID [90] (3.0-6.6)

NEPSY ${ }^{\circledR}[177](5-16)$

NEPSY ${ }^{\circledR}[177](5-16)$

NEPSY ${ }^{\circledR}$ [177]

(3-16)

(3-6)

(5-16)

KET-KID [90]

(3.0-6.6)

VLMT [151] (6-79)

WPPSI-III [336]

KABC-II [167] (3-18)

SON-R [317] 2 1/2-7

HAWIK-IV [238]

AID-2 [182]

SON-R 5 1/2-17 [316]

SLRT-II [218]

ZAREKI-R [358]

BRIEF $^{\circledR}[103]$

(6-16)

BRIEF-P ${ }^{\circledR}$ [89]

(2-6)

NEPSY ${ }^{\circledR}$ [177]

(5-12)

(3-6)

(5-16)

TAP [356] (6-18)

KITAP [357] (6-10)

T.O.V.A. [318] $\geq 4 / 6$

FWIT [30] 10-85 


\begin{tabular}{|c|c|c|}
\hline Funktionsbereich & Instrumente & $\begin{array}{l}\text { Abkürzung, Alters- } \\
\text { norm, Literatur }\end{array}$ \\
\hline Arbeitsgedächtnis & $\begin{array}{l}\text { Siehe oben und Subtest der Testbatterie zur Aufmerksamkeitsprü- } \\
\text { fung: Arbeitsgedächtnis }\end{array}$ & TAP [356] (10-18) \\
\hline \multirow[t]{6}{*}{ Planen, Organisieren und Problemlösen } & $\begin{array}{l}\text { z. B. Subtest des Developmental Neuropsychological Assessment }{ }^{\circledR} \text { : } \\
\text { Clocks }\end{array}$ & NEPSY ${ }^{\circledR}[177](7-16)$ \\
\hline & Osnabrücker Turm von Hanoi & TvH [129] \\
\hline & Turm von London & $\operatorname{TvL}[325](\geq 11)$ \\
\hline & Zoo-Spiel & [122] $(6-15$, ab 18) \\
\hline & $\begin{array}{l}\text { Subtest des Hamburg-Wechsler-Intelligenz-Tests für Kinder: Laby- } \\
\text { rinthtest }\end{array}$ & $\begin{array}{l}\text { HWIK-IV [238] } \\
(6.0-16.11)\end{array}$ \\
\hline & $\begin{array}{l}\text { Subtest der Testbatterie zur Aufmerksamkeitsprüfung bzw. der } \\
\text { Kinderversion }\end{array}$ & $\begin{array}{l}\text { TAP [356]/KITAP [357] } \\
(9-12 / 6-10)\end{array}$ \\
\hline Flexibilität & $\begin{array}{l}\text { z. B. Subtest des Developmental Neuropsychological Assessment }{ }^{\circledR} \text { : } \\
\text { Animal Sorting }\end{array}$ & NEPSY ${ }^{\circledR}[177](7-16)$ \\
\hline \multirow{3}{*}{$\begin{array}{l}\text { Kognitive Flexibilität } \\
\text { Wahrnehmungsflexibilität } \\
\text { Handlungsflexibilität }\end{array}$} & Wisconsin Card Sorting Test & WCST-64 [138] (6.5-89) \\
\hline & Trail Making Test $B$ & TMT [47] \\
\hline & $\begin{array}{l}\text { Subtest der Testbatterie zur Aufmerksamkeitsprüfung bzw. der } \\
\text { Kinderversion: Flexibilität }\end{array}$ & $\begin{array}{l}\text { TAP [356]/KITAP [357] } \\
(9-12 / 6-10)\end{array}$ \\
\hline \multirow[t]{2}{*}{ Konzeptbildung } & \multirow{2}{*}{$\begin{array}{l}\text { z. B. Subtest des Developmental Neuropsychological Assesment }{ }^{\circledR} \text { : } \\
\text { Animal Sorting } \\
\text { Wisconsin Card Sorting Test }\end{array}$} & NEPSY ${ }^{\circledR}[177](7-16)$ \\
\hline & & WCST-64 [138] (6.5-89) \\
\hline $\begin{array}{l}\text { Serialität } \\
\text { (Antizipieren) }\end{array}$ & $\begin{array}{l}\text { z. B. Subtest des Hamburg-Wechsler-Intelligenztests für Kinder: } \\
\text { Bilder ordnen }\end{array}$ & $\begin{array}{l}\text { HAWIK-IV [238] } \\
(6.0-16.11)\end{array}$ \\
\hline \multirow[t]{2}{*}{$\begin{array}{l}\text { Flüssigkeit } \\
\text { Verbal }\end{array}$} & z. B. Regensburger Wortflüssigkeitstest & $\begin{array}{l}\text { RWT }[17] \\
(8-15, a b \text { 18) }\end{array}$ \\
\hline & $\begin{array}{l}\text { Subtest des Developmental Neuropsychological Assessment }{ }^{\circledR} \text { : Word } \\
\text { Generation }\end{array}$ & NEPSY ${ }^{\circledR}[177](5-12)$ \\
\hline Non-verbal & $\begin{array}{l}\text { Subtest des Developmental Neuropsychological Assessment }{ }^{\circledR} \text { : De- } \\
\text { sign Fluency }\end{array}$ & NEPSY ${ }^{\circledR}[177](5-12)$ \\
\hline \multicolumn{3}{|l|}{ Komorbide Erkrankungen } \\
\hline \multirow[t]{2}{*}{ Depression } & z. B. Depressionsinventar für Kinder & DIKJ [308] (8-16) \\
\hline & Beck Depressionsinventar II & BDI-II [33] (ab 13) \\
\hline Angst & z. B. Phobiefragebogen für Kinder und Jugendliche & PHOKI [99] (8-18.11) \\
\hline \multicolumn{3}{|l|}{ Persönlichkeitsdiagnostik - fakultativ } \\
\hline Temperament & \multirow[t]{4}{*}{ z. B. Junior Temperament und Charakterinventar } & JTCI [137] \\
\hline $\begin{array}{l}\text { Fremdbeurteilung } \\
\text { Vorschulalter }\end{array}$ & & JTCI 3-6R (3-6) \\
\hline $\begin{array}{l}\text { Fremdbeurteilung } \\
\text { Grundschulalter }\end{array}$ & & JTCI 7-11 R (7-11) \\
\hline Selbstbeurteilung & & JTCl 12-18 R (12-18) \\
\hline $\begin{array}{l}\text { Verhaltensstile } \\
\text { Motive, Selbstbild Aspekte }\end{array}$ & z. B. Persönlichkeitsfragebogen für Kinder zwischen 9 und 14 Jahren & PFK [287] (9-14) \\
\hline
\end{tabular}

tik (• Tab. 2) bewährt, wobei die Empfehlung Testverfahren, die rezent aktualisiert wurden, berücksichtigt:

\section{Therapie}

Es gibt noch keine kurative Therapie des ADHS [197]. Seit der Entdeckung der Wirkung von Benzedrin (Amphetamin) gegen Aufmerksamkeits- und Verhaltensprobleme durch Charles Bradley (1937, 1950 [77]), insbesondere seit der Synthese von MPH durch Leandro Panizzon (1944) und der Entwicklung retardierter Präparate ${ }^{7}$ [62] sind vor allem Kinder mit schweren Formen von

7 Bimodal (kurz- und verzögert) wirksames MPH, MPH OROS („osmotic controlled-release oral delivery system“, 2001), Concerta ${ }^{\circledR}$, bzw. Ritalin $\mathrm{LA}^{\circledR}$, und Medikinet retard ${ }^{\circledR}$ und ein der-
ADHS nicht mehr zu unangepasstem Verhalten, sozialem Außenseitertum, Schul- und beruflichem Versagen verurteilt. Mehr als 250 kontrollierte Studien belegen die Sicherheit, Verträglichkeit und gute Wirkung von Stimulanzien gegen die Hauptsymptome des ADHS.

zeit nur in den USA erhältliches, transdermales $\mathrm{MPH}$, Daytrana ${ }^{\circledR}$. 
Ein weiterer Meilenstein war die Entdeckung der konzentrationsfördernden Eigenschaften des Noradrenalin-Wiederaufnahmehemmers ATX (Strattera ${ }^{\circledR}$, Lilly), das eine kontinuierlichere Wirkung als MPH entfaltet und auch Tics positiv beeinflussen kann. ATX hat sich auch bei der Besserung angstbezogener komorbider Probleme bewährt [247]. Neuere pharmakologische Entwicklungen wie flüssige oder transdermale Applikationen können möglicherweise die Adhärenz in der Langzeittherapie verbessern [85].

Behandlungsziele sind vor allem Symptomreduktion (s. unten) und Verbesserung der Lebensqualität [75] in allen Lebensbereichen, nicht nur im Schulsetting. Diese Ziele werden vor allem mit multimodaler Therapie, Verhaltenstherapie, Elternschulung und Pharmakotherapie mit retardiertem MPH, Lisdexamphetamin oder ATX in der Mehrzahl der Fälle erreicht $[113,146,168]$. Langzeitstudien belegen die Erfolge pharmakologischer Langzeittherapie sowohl für die Verbesserung von Strukturdefiziten [123, 204, 248, 331] als auch für die Reduktion von Verhaltensauffälligkeiten, emotionaler Labilität [64], Schulversagen [31], Unfallrisiko[291], Risiko von Substanzmissbrauch und Computerabhängigkeit [61]. Absolute Kontraindikationen sind Unverträglichkeit und Therapie mit Monoaminooxydase(MAO)-Hemmer. Relative Kontraindikationen sind bestimmte Herzfehler, arterielle Hypertonie und eine Neigung $\mathrm{zu}$ supraventrikulären Tachykardien [207] ${ }^{8}$.

Stimulanzien zeigen eine klinisch messbare Wirkung bei 73-77\% der Schulkinder. Vorschulkinder und Erwachsene haben eine größere Reaktionsbreite bzw. benötigen oft nur geringe Dosen [77]. Einen Überblick über die pharmakolo-

\footnotetext{
8 Die kardialen Risiken sind in Kooperation mit der Kinderkardiologie zu klären und das Behandlungsrisiko gegenüber einem Behandlungsgewinn abzuwägen. Dies gilt insbesondere für supraventrikuläre Tachykardien, die vorbeugend mit einem $\beta$-Blocker oder bei entsprechender Indikation mittels Katheterablation behandelt werden können. Ein initiales Routine-Elektrokardiogramm und gelegentliche Blutdruckmessungen werden empfohlen.
}

gischen Eigenschaften der Stimulanzien gibt eine rezente Arbeit von Faraone [107]. MPH-Non-Responder bessern sich oft durch Umstellung auf Lisdexamphetamin, Amphetamin, ATX, seltener Guanfacin (s. unten) oder die Kombination von $\mathrm{MPH}+\mathrm{ATX}$. Wirksamkeit und Verträglichkeit von MPH wurden in 185 randomisierten und 260 nichtrandomisierten Studien eindrücklich belegt [309]. Die verschiedenen retardierten MPH-Präparate unterscheiden sich in ihrer Halbwertszeit, wobei Concerta ${ }^{\circledR}$ die längste $(10-14 \mathrm{~h})$, Ritalin $\mathrm{LA}^{\circledR}(8 \mathrm{~h})$ die kürzeste Wirkdauer besitzt. Die Wirkdauer von Medikinet $\operatorname{retard}^{\circledR}$ liegt dazwischen, dieses Präparat zeichnet sich durch eine relativ rasche Anflutung aus. Die Vielfalt der Wirkdauern erleichtert die MPH-Einstellung. Es gibt (wenige) „slow" "bzw. „rapid metabolizer“, also Personen, die MPH bzw. Strattera langsamer oder schneller verstoffwechseln, weshalb man vor allem beim Auftreten unerwünschter Nebenwirkungen und bei raschem Wirkungsabfall immer auch an Metabolisierungsprobleme denken muss. Vorschulkinder haben eine längere MPH-Halbwertszeit [340], sie sollten nur bei ausgeprägter Symptomatik bzw. nach entsprechender Verhaltenstherapie [243], Elterntraining (z.B. Incredible Years Program $[164,221]$, Triple $P[46$, 273], Parent-Child Interaction Therapy, PCIT [322]) und/oder Ergotherapie mit MPH behandelt werden [65].

Amphetamine [205, 251] sind (wie auch $\mathrm{MPH}$ ) als 1-und r-Enantiomere verfügbar, wobei die r-Form wirksamer ist. Es gibt in Deutschland auch ein reines Dexamphetaminpräparat: Attentin ${ }^{\circledR}$ (Medice). Amphetamin besitzt im Gegensatz zu MPH ${ }^{9}$ Suchtpotenzial, da es euphorisierend und antidepressiv wirkt. Lisdexamphetamin ${ }^{10}$ [117] wird im Darm zu Dexamphetamin hydrolysiert und besitzt kaum Suchtpotenzial ${ }^{11}$. Amphetamine werden vor allem sekundär bei $\mathrm{MPH}-$ Therapieversagen emp-

\footnotetext{
${ }^{9}$ Ausnahme i.v.

${ }^{10}$ In Deutschland und Österreich Elvanse ${ }^{\circledR}$ (Shire).

11 In Österreich ist Lisdexamphetamin daher auch nicht auf dem Suchtgiftindex.
}

fohlen. Ein weiterer Vorteil ist, dass Lisdexamphetamin in Flüssigkeit aufgelöst werden kann [246].

Nebenwirkungen der Stimulanzientherapie sind vor allem Appetitmangel, gastrointestinale [157] und Schlafprobleme. Kinder mit ADHS neigen primär zu Schlafproblemen [44, 147, 278]. Schlafprobleme können auch ADHSSymptome bedingen oder verstärken [115], sind aber auch Teil der Nebenwirkungen der Stimulanzientherapie [66]. Therapeutisch kommen vor allem Schlafhygiene und Melatonin [51] infrage. Kardiovaskuläre Probleme sind eher gering bzw. selten [191]. Weitere Nebenwirkungen können sich in Kopfund Magenschmerzen, depressiver Verstimmung, Reizbarkeit, Traurigkeit und sehr selten bei Überdosierung bzw. langsamer Metabolisierung in psychotischen Symptomen manifestieren [208]. Aggressivität ist keine Kontraindikation gegen Stimulanzientherapie. Initiale Verstärkung einer Ticneigung bessert sich oft nach etwa 2 Wochen Therapiedauer. $\mathrm{Ob}$ längerdauernde Stimulanzientherapie das Wachstum beeinträchtigt, wird widersprüchlich diskutiert [261, 324]. Nebenwirkungen der Amphetamintherapie werden etwas häufiger als bei $\mathrm{MPH}$ beobachtet [77].

Die Ergebnisse der MTA [320, 321] zeigten, dass die Kombination MPH und intensive, 14 Monate dauernde Verhaltenstherapie etwa gleich gute Verbesserungen der ADHS-Symptomatik im Vergleich zu nur MPH brachten, dass aber internalisierende Symptome, soziale Kompetenz, Eltern-Kind-Beziehung und Leseleistungen sich unter der kombinierten Therapie deutlicher besserten. Beim ersten Follow-up nach 10 Monaten waren die ADHS-ScoreEffekte nur mehr halb so gut und nach 3 Jahren [162] bei leichter Verbesserung in allen Therapiegruppen nicht mehr signifikant unterschiedlich. Nach 8 Jahren [217] gab es zwar weiterhin leichte Verbesserungen, aber keine signifikanten Gruppenunterschiede und die Ergebnisse unterschieden sich weiterhin deutlich von denen der Nicht-ADHSKontrollkinder, obwohl nur mehr 30\% der Patientinnen und Patienten die Diagnosekriterien für ADHS erfüllten. Die 
Autoren zogen den Schluss, dass die initiale Symptomatik (ADHS-Symptome, Verhaltensprobleme, intellektuelle Leistungsfähigkeit, sozialer Hintergrund, Komorbidität) auch den weiteren Verlauf des ADHS bestimmt. Dazu kommt, dass die Medikamentenadhärenz in der Studienpopulation nicht sehr groß war (nur etwa $20 \%$ nahmen MPH während der gesamten Nachbeobachtungsperiode ein). Daher empfehlen die MTAAutoren individuelle Medikation mit wiederholten Absetzversuchen. Bei persistierender ADHS-Symptomatik zeigt sich, dass sich die ADHS-Symptomatik während des Absetzversuchs verschlechtert [209]. Daher und auch wegen der negativen Konsequenzen in der Transitionszeit [342] im Erwachsenenalter [259] sollte die Therapie bei persistierender Symptomatik auch über das Adoleszenzalter hinaus fortgesetzt werden. Die Langzeiteffekte sind eher positiv, strukturelle und Verhaltensremissionen nach längerfristiger MPH-Therapie, geringere Depressions- und Suizidraten [178].

Das Risiko missbräuchlicher Stimulanzienverwendung insbesondere bei Studenten ist relativ hoch mit einer großen Streubreite $(0,7-80 \%$; [111]) und sollte daher immer berücksichtigt werden. Nichtansprechen auf Stimulanzientherapie erfordert einen Wechsel auf andere Substanzklassen wie Noradrenalin-Wiederaufnahmehemmer, Alpha-2Agonisten oder andere, in diesem $\mathrm{Zu}$ sammenhang weniger erforschte Substanzen [292].

\section{Noradrenalin-Wiederaufnahmehem-}

mer. ATX ${ }^{12}$ wurde erstmals 1998 bei Erwachsenen bzw. 2001 erstmals bei Kindern mit ADHS untersucht. Seither haben 25 kontrollierte Studien [161, 286] eine im Vergleich zu Stimulanzien etwas geringere Effektivität im Hinblick auf die Kardinalsymptome des ADHS bescheinigt. Die Therapie mit ATX ist etwas schwieriger einzustellen als mit Stimulanzien, da die Wirkung langsamer bzw. erst nach mehreren (bis zu 12) Wochen eintritt und zunächst vermehrte Kreislaufnebenwirkungen beobachtet werden

\footnotetext{
12 Strattera ${ }^{\circledR}$, Lilly und Generica.
}

können. Bei etwa 10-15\% der Kinder treten Nebenwirkungen wie besondere Müdigkeit und vermehrte Aggressivität auf, wobei unklar ist, ob diese als Teil des ADHS-Spektrums zu sehen ist, die unter der Therapie vermehrt auffällt oder als Nebeneffekt auftritt [256]. Jedenfalls war der Unterschied zur Kontrollgruppe hinsichtlich dieses Parameters in einer Metaanalyse nicht signifikant [286]. Genetische Cytochrom-p450-Polymorphismen sind vermutlich für Unterschiede in der Elimination von ATX verantwortlich [49]. Es gibt Hinweise, dass ähnlich wie bei MPH strukturelle Langzeiteffekte möglich sind [72].

Alpha-2-Agonisten. (Clonidin, Lofexidin und Guanfacin) wurden neben ihrer antihypertensiven Wirkung auch gegen Tics verwendet. Ihr therapeutischer Einsatz bei ADHS ist von niedrigen Effektstärken in Bezug auf die Kardinalsymptome (g um 0,35) gekennzeichnet, sie punkten aber bei der Therapie aggressiver und oppositioneller Verhaltensweisen, bei stimulanzieninduzierten Schlafstörungen und als Alternative bzw. Kombinationstherapie bei Stimulanzienversagen [16, 42, 63, 143]. Der Wirkmechanismus sei insbesondere auf die Stimulation präfrontaler postsynaptischer $a$-2A-Rezeptoren zurückzuführen, die verhaltensinhibitorisch und das Arbeitsgedächtnis verbessernd wirken [78]. Verzögert wirksames Guanfacin kann oppositionelles Verhalten positiv beeinflussen, wenn Stimulanzien allein nicht ausreichen [114]. Nebenwirkungen der a-2-Agonisten sind Müdigkeit, Reizbarkeit, Bradykardie und Kreislaufprobleme (Hypotension, Kopfschmerzen und gastrointestinale Symptome).

Die Leitlinien der deutschen Arbeitsgemeinschaft der Wissenschaftlichen Medizinischen Fachgesellschaften (AWMF) [94] und der American Academy of Child and Adolescent Psychiatry [140] empfehlen die Verschreibung von Stimulanzien und Atomoxetin nur nach sorgfältiger Abklärung und entsprechender Indikationsstellung. Eine Dosierungsempfehlung findet sich in - Tab. 3.
Atypische Neuroleptika. Aripiprazol, Clozapin, Olanzapin, Quetiapin, Risperidon und Ziprasidon haben sich bei nicht ausreichender Wirkung von Stimulanzien bzw. ATX und sozialpsychiatrischen bzw. psychotherapeutischen Problemen in möglichst niedriger Dosierung bewährt [196, 290, 337]. In einer retrospektiven Studie über 1,5 Jahre wurden $25 \%$ der stationär aufgenommenen Kinder mit ADHS zusätzlich neuroleptisch behandelt [250], wobei mehr als die Hälfte der Kinder und Jugendlichen Risperidon erhielten. Für die Anwendung typischer Neuroleptika wie Haloperidol und die Kombination mehrerer Neuroleptika gibt es wegen der klaren Nebenwirkungsnachteile (Sedierung, Dyskinesien, hämatologische, metabolische und hepatale Probleme) nur wenige Indikationen außer der Hilflosigkeit der Therapeutinnen und Therapeuten bei sehr aggressiven Kindern und Jugendlichen, die eher von sozialpsychiatrischen, Jugendwohlfahrts- und erlebnispädagogischen Interventionen zusätzlich zur konventionellen Medikation profitieren.

Kritiker bemängeln, dass die Wirkung von Stimulanzien bzw. ATX und Neuroleptika entgegengesetzt sei: die einen würden als indirekte Agonisten die Verfügbarkeit von Dopamin am Rezeptor vermehren, die anderen als Antagonisten verringern. Auch sei der Wirkmechanismus ungeklärt. Dagegen wird eingewandt, dass unterschiedliche Wirkorte und Rezeptoren betroffen seien ${ }^{13}$ und dass die klinische Wirksamkeit unbestritten sei [234]. Es gibt leider nur wenige prospektive Kombinationsstudien [189]. Die Empfehlung lautet daher, Neuroleptika nicht isoliert, sondern eingebettet in psychosoziale Interventionen in der Therapie einzusetzen, zumal sich die Kombination aus Neuroleptika und situativen verhaltenstherapeutischen Ansätzen (z. B. Belohnungsstrategien, Kontingenzmanagement) positiv auf das Verhalten auswirken [284].

Verschiedene Leitlinien ([94, 140, 225], und andere) sollen evidenzba-

\footnotetext{
13 Mesokortikale Dopaminvermehrungundautoinhibitorische Downregulation des nigrostriatalen dopaminergen Systems vs. Blockade mesolimbischerD2-Rezeptoren.
} 


\begin{tabular}{|c|c|c|c|c|c|}
\hline Präparat & Inhaltsstoff & Verfügbare Dosierungen & $\begin{array}{l}\text { Anwen- } \\
\text { dung }\end{array}$ & $\begin{array}{l}\text { Dosierung } \\
\text { [mg/kg KG] }\end{array}$ & Bemerkungen \\
\hline $\begin{array}{l}\text { Ritalin }^{\circledR}(\text { Novartis } \\
\text { Pharma GmbH) }\end{array}$ & Methylphenidat & $10 \mathrm{mg}$, Tablette & $3 \times \operatorname{tgl}$ & $0,2-0,3$ & Wirkdauer 4-6h \\
\hline $\begin{array}{l}\text { Medikinet }{ }^{\circledR} \text { (Medice } \\
\text { Arzneimittel Pütter } \\
\text { GmbH \& Co KG) }\end{array}$ & Methylphenidat & $10 \mathrm{mg}$, Tablette & $3 \times \operatorname{tgl}$ & $0,2-0,3$ & Wirkdauer 4-6h \\
\hline $\begin{array}{l}\text { Amphetaminsulfat } \\
\text { ÖAB }\end{array}$ & $\mathrm{d} / \mathrm{I}$ Amphetamin & $\begin{array}{l}\text { Kapsel individuell nach Bedarf (eventuell } \\
\text { in etwas Flüssigkeit auflösen) }\end{array}$ & $1-2 \times \operatorname{tgl}$ & 0,15 & Wirkdauer 6-8h \\
\hline $\begin{array}{l}\text { Ritalin LA }{ }^{\circledR} \text { (Novar- } \\
\text { tis) }\end{array}$ & Methylphenidat & 20, 30, 40 mg, Kapsel & $1 \times \operatorname{tgl}$ & $0,5-1$ bis maximal 3 & Wirkdauer 8-10 h \\
\hline $\begin{array}{l}\text { Medikinet ret }{ }^{\circledR} \\
\text { (Medice) }\end{array}$ & Methylphenidat & $5,10,20,30,40$ mg, Kapsel & $1 \times \operatorname{tgl}$ & $0,5-1$ bis maximal 3 & Wirkdauer $10-12 \mathrm{~h}$ \\
\hline $\begin{array}{l}\text { Concerta }^{\circledR} \text { (Jans- } \\
\text { sen-Cilag Pharma } \\
\text { GmbH) }\end{array}$ & Methylphenidat & $18,27,36,54$ mg, Kapsel & $1 \times \operatorname{tgl}$ & $0,5-1$ bis maximal 3 & Wirkdauer 10-14h \\
\hline $\begin{array}{l}\text { Strattera }^{\circledR} \text { (Lilly } \\
\text { GmbH) }\end{array}$ & Atomoxetin & $10,18,25,40,60,80,100$ mg, Kapsel & $1 \times \operatorname{tgl}$ & $\begin{array}{l}0,5 \text { (1. Woche), dann } \\
1,3\end{array}$ & $\begin{array}{l}\text { Wirkdauer } 24 \mathrm{~h} \text {, verzöger- } \\
\text { ter Wirkungseintritt }\end{array}$ \\
\hline $\begin{array}{l}\text { Catapresan }^{\circledR} \text { (Boeh- } \\
\text { ringer Ingelheim } \\
\text { RCV GmbH \& Co KG) }\end{array}$ & Clonidin & $0,150 \mathrm{mg}$, Tablette & $2 \times \operatorname{tgl}$ & $0,0015-0,003$ & $\begin{array}{l}\text { Wirkdauer 8-12 h, verzö- } \\
\text { gerter Wirkungseintritt }\end{array}$ \\
\hline $\begin{array}{l}\text { Intuniv }{ }^{\circledR} \text { (Shire } \\
\text { Pharmaceuticals } \\
\text { Ireland Ltd) }\end{array}$ & Guanfacin ER & 1,2,3,4 mg, Tablette & $1 \times \operatorname{tgl}$ & 0,05 & $\begin{array}{l}\text { Wirkdauer } 24 \mathrm{~h} \text {, verzöger- } \\
\text { ter Wirkungseintritt }\end{array}$ \\
\hline
\end{tabular}

sierte, diagnostische und therapeutische Standards sichern und optimale Behandlungsergebnisse ermöglichen. Dies ist umso notwendiger, als viele Eltern durch Alternativtherapie gläubige, evidenzlose, medikationsfeindliche Webkampagnen verunsichert werden. Alle Leitlinien gehen von multiprofessioneller Diagnostik und einem multimodalen Therapiekonzept aus. Bei Einhaltung klarer diagnostischer Kriterien und sorgfältiger individueller Therapieplanung überwiegen die Vorteile der Medikation, die vor allem den betroffenen Kindern eine ihrem Potenzial entsprechende Ausbildung und Lebensqualität sichern soll, klar deren Nachteile.

ADHS und Epilepsie. Epilepsie ist eine im Kindes- und Jugendalter relativ häufige Erkrankung $^{14}$, bei der auch das Risiko für intellektuelle Beeinträchtigung und ADHS auf etwa 20-50\% deutlich erhöht ist $[35,329,345]$. Dabei ist es - vermutlich aufgrund der Heterogenität der Erkrankung - unklar, inwieweit die Erkrankung (z.B. dysfunktionale Neurotransmission) oder die notwendige Medikati-

14 Prävalenz3,2-5,5. on an der hohen Komorbidität beteiligt sind. Phenobarbital, Valproinsäure, Phenytoin, Topiramat und Ethosuximid haben einen negativen, Carbamazepin und Lamotrigin einen positiven, und Levetiracetam, Oscarbazepin, Gabapentin und Vigabatrin einen neutralen Effekt auf das Verhalten, die kognitive Leistungsfähigkeit und die ADHS-Symptomatik [329]. Für Pregabalin gibt es keine publizierten Daten. Die Wirkung von Stimulanzien und ATX auf die Anfallshäufigkeit ist unklar; bisherige Studien belegen eher eine Verringerung der Anfallsfrequenz [329].

Nichtpharmakologische Therapie. Sozialpsychiatrische, psychosoziale und psychotherapeutische Interventionen sind unumgänglich bei einem Krankheitsbild, das auch durch die Umgebung und intraindividuelle Reaktionen in seinen Erscheinungsformen geprägt wird [2, 154]. Auch wenn die MTA Pessimismus hinsichtlich des Vorteils zusätzlicher psychosozialer Therapie und der Nachhaltigkeit der Interventionen bezogen auf die Kernsymptomatik verbreitet hat, geht aus der Studie klar hervor, dass das komplexe Bild des ADHS mit seinen komorbiden, insbesondere sozialen Problemen auch sozio- und psycho- therapeutisch gebessert werden kann [302].

Nichtpharmakologische Therapie wie Ergotherapie, Bio- und Neurofeedback [8, 15, 255, 296], psychologische und Verhaltenstherapie (s. unten), kognitives Training[84, 294, 305] und Sport [150] sind insbesondere als Zusatztherapie bzw. zur Besserung der EF erfolgreich [24, 68, 158, 252, 302]. Ergotherapie ist trotz kritischer Kommentare [11] vor allem wegen der Besserung dysexekutiver Probleme die Therapie der Wahl, insbesondere im Vor- und Primärschulalter [144, 200]. Auffällig ist eine relativ hohe Streubreite der Effektstärken nichtpharmakologischer Therapie [262], die vorwiegend durch methodische und persönliche Heterogenität erklärbar sein dürfte. Diät [59, 93, 198, 237], pflanzliche Arzneimittel [13], Elimination von Lebensmittelfarben, Schwermetallentgiftung, Homöopathie etc. [20, 307] zeigen keine nachweisbare Effizienz. Trotz einiger erfolgversprechender Einzelstudien zeigen Metaanalysen eine nur geringe Wirksamkeit von Omega3-Fettsäuren [1, 80, 236, 237, 249, 302]. Für Eliminationsdiät („few food diet“) zeigen sich möglicherweise in Abhängigkeit vom Allergierisiko [215, 279] 
interessante Effekte als ADHS-spezifische Nahrungsergänzungstherapie.

Sozialpsychiatrische und -therapeutische Maßnahmen umfassen Aufklärung der Familienmitglieder und der Pädagoginnen und Pädagogen über die Probleme des ADHS und der Komorbiditäten, den verständnisvollen Umgang mit den Kindern, das Nicht-persönlichNehmen von Ungeduld, Planungsproblemen, Erst-Handeln-dann-Denken usw. Erfolgreiche Strategien sind Planen der Tagesstruktur, Strukturieren und Aufteilen von Aufgaben, positives Denken und Nichtvergessen von Lob und sozialer Verstärkung [73]. Bei Problemfamilien sind auch intensivere Unterstützungsprogramme erfolgreich [76].

Individuelle und Gruppentherapien zielen auf eine Verbesserung des Verhaltens, der Konzentrationsfähigkeit, der Eltern-Kind-Beziehung und der Schulleistungen ab [168]. Achtsamkeitsbasierte Therapien können Aufmerksamkeit und Selbstregulation verbessern [282]. Evaluierte Programme wie THOP [101], ein verhaltenstherapeutisches Eltern-, Einzel- und Gruppentrainingsprogramm, hilft, ein ADHS-Störungskonzept zu erarbeiten, fördert positive Eltern-KindInteraktionen, identifiziert, bekämpft und hilft, impulsives und oppositionelles Problemverhalten zu verändern. Spezifische Verhaltensprobleme werden bearbeitet, angemessene Verhaltensweisen, positives Spielverhalten und reflexives, planvolles Arbeitsverhalten werden gefördert und generalisiert. THOP kann durch das Präventionsprogramm für expansives Problemverhalten (PEP) mit einem Eltern- und einem Erziehermodul ergänzt werden [245]. Das Marburger Konzentrationstraining (MKT) für Vorschulkinder [180] bzw. Schulkinder [179] soll strukturiertes Denken und Konzentrationsfähigkeit verbessern. Eine Metaanalyse [86] zeigt, dass elterliches Erziehungsverhalten und Selbstkonzept, ADHS-Symptome und das Sozialverhalten unter kognitiver Verhaltenstherapie signifikant verbessern. Für Jugendliche sind auch kognitiv behaviorale Therapien, die sich primär bei Erwachsenen bewährt haben, geeignet [216, 271]. Sie beinhalten Psychoedukation, Verhaltenstraining und kognitive Elemente, die gegen dysfunktionale Selbstabwertungen und deren Konsequenzen gerichtet sind.

Elterntraining soll die elterliche Erziehungskompetenz stärken, wobei die Nachhaltigkeit von Trainingsprogrammen nicht sicher gewährleistet erscheint [168, 185, 217, 359]. Die Frage der Messbarkeit des elterlichen Erziehungsverhaltens ist allerdings nicht geklärt. Bewährte und evaluierte Elterntrainingsprogramme sind z.B. Wackelpeter und Trotzkopf [102] und das Triple P, Positive Parenting Program [274].

\section{Prognose}

ADHS ist eine chronische Erkrankung, die unbehandelt zu starken Einbußen der Leistungsfähigkeit und Lebensqualität führt [27]. Auch wenn sich die Hyperaktivitätssymptome im Lauf der Pubertät bessern, bleiben Aufmerksamkeits- und Impulsivitätsprobleme und die komorbiden Probleme ohne Behandlung weiterhin leistungseinschränkend und prädisponieren für Schwierigkeiten am Arbeitsplatz, in der Emotionsregulation, in den persönlichen Beziehungen und fördern psychosomatische Probleme und Depression. Die Persistenz der Probleme wird vorwiegend durch den sozialen und ökonomischen Hintergrund sowie den Schweregrad der kognitiven Beeinträchtigung bestimmt [171]. Weitere Faktoren für das Persistieren des ADHS sind (multimodale) Behandlung, komorbide Verhaltens- und depressive Störung [56]. Einige Autoren empfehlen daher lebenslange (medikamentöse) Therapie, zumindest bei den rund $60 \%$ der Patientinnen und Patienten, bei denen die Kardinalsymptome persistieren. Diese Medikation wird aber nur von einem Bruchteil der Betroffenen verwendet [260]. In einer großen Fragebogenstudie erinnerten sich die meisten Erwachsenen, schulleistungsmäßig schlechter gewesen, mehr Verhaltensauffälligkeiten, weniger Freunde und schlechtere Erinnerungen an die Jugendzeit gehabt $\mathrm{zu}$ haben und dass sich diese negativen Erfahrungen auch bis ins Erwachsenenalter fortgesetzt haben [53]. Zusätzlich werden die transgenerationalen Probleme durch Armutsgefährdung und
Selbsttherapie mit Alkohol und ev. Drogen verstärkt. Ein Problem sind auch die Nicht-ADHS-Mütter, die mit den ihnen nicht bekannten ADHS-Problemen der Kinder konfrontiert sind.

Ein Problem ist die Transition jugendlicher Patientinnen und Patienten ins Erwachsenenalter [229]: Einerseits sinkt in der Pubertät die Bereitschaft, laufend Medikamente zu nehmen, andererseits gibt es nur wenige ADHS-erfahrene Erwachsenenpsychiater, die eine weitere fachgerechte Behandlung übernehmen können.

Trotz deutlicher klinischer Verbesserungen und eindeutig besserer Prognose unter medikamentöser Therapie geben die Befunde eines deutlichen und persistierenden Unterschieds zu Nicht-ADHSKindern bis ins Erwachsenenalter zu denken. Die schlechte Prognose insbesondere bei Außenseiterkindern mit schwer auffälligem Sozialverhalten, desolaten Familienstrukturen, wehrlosen, überforderten und resignierenden Eltern und Einzelerzieherinnen und -erziehern sowie die Tatsache, dass Jugendkriminalität mit sehr hoher ADHS-Komorbidität korreliert ist [240, 352], wirft die Frage auf, inwieweit multimodale, früh einsetzende, präventive Konzepte [79], transgenerationale Armutsbekämpfung, intensive sozialtherapeutische Programme [76] und zusätzliche Therapieoptionen wie fortgesetztes Familiencoaching, intensive schulische und Freizeitangebote als zusätzliche, maßgeschneiderte Maßnahmen insbesondere bei diesen Risikogruppen erfolgreich sein können. Wenn auch die "goldene Kugel“ insbesondere bei diesen Risikogruppen noch nicht gefunden ist, ermutigen die Therapieerfolge bei einem Großteil der Kinder, die zumindest eine adäquate Ausbildung vollenden können und dank Medikation auch deutlich weniger ausgegrenzt werden. Künftige Forschungsziele sind vor allem Behandlungsergebnisse jenseits der Symptomkontrolle, Fragen der Medikamentensicherheit und der Wirksamkeit im Alltagsleben [349]. 


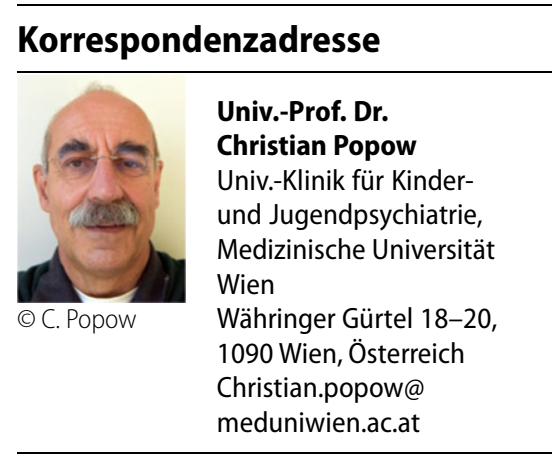

Funding. Open access funding provided by Medical University of Vienna.

\section{Einhaltung ethischer Richtlinien}

Interessenkonflikt. C. Popow und S. Ohmann haben für die Publikation des Beitrags finanzielle Unterstützung von der Firma Medice erhalten.

Für diesen Beitrag wurden von den Autoren keine Studien an Menschen oder Tieren durchgeführt. Für die aufgeführten Studien gelten die jeweils dort angegebenen ethischen Richtlinien.

Open Access. Dieser Artikel wird unter der Creative Commons Namensnennung 4.0 International Lizenz veröffentlicht, welche die Nutzung, Vervielfältigung, Bearbeitung, Verbreitung und Wiedergabe in jeglichem Medium und Format erlaubt, sofern Sie den/die ursprünglichen Autor(en) und die Quelle ordnungsgemäß nennen, einen Link zur Creative Commons Lizenz beifügen und angeben, ob Änderungen vorgenommen wurden.

Die in diesem Artikel enthaltenen Bilder und sonstiges Drittmaterial unterliegen ebenfalls der genannten Creative Commons Lizenz, sofern sich aus der Abbildungslegende nichts anderes ergibt. Sofern das betreffende Material nicht unter der genannten Creative Commons Lizenz steht und die betreffende Handlung nicht nach gesetzlichen Vorschriften erlaubt ist, ist für die oben aufgeführten Weiterverwendungen des Materials die Einwilligung des jeweiligen Rechteinhabers einzuholen.

Weitere Details zur Lizenz entnehmen Sie bitte de Lizenzinformation auf http://creativecommons.org/ licenses/by/4.0/deed.de.

\section{Literatur}

1. Abdullah M, Jowett B, Whittaker PJ, Patterson L (2019) The effectiveness of omega-3 supplementation in reducing ADHD associated symptoms in children as measured by the Conners' rating scales: A systematic review of randomized controlled trials. J Psychiatr Res 110:64-73. https://doi.org/ 10.1016/j.jpsychires.2018.12.002

2. Abikoff H (2009) ADHD psychosocial treatments. J Atten Disord 13(3):207-210. https://doi.org/10. 1177/1087054709333385

3. Abikoff H, McGough J, Vitiello B, McCracken J, Davies M, Walkup J, Riddle M, Oatis M, Greenhill L, Skrobala A, March J, Gammon P, Robinson J,
Lazell R, McMahon DJ, Ritz L (2005) Sequential pharmacotherapy for children with comorbid attention-deficit/hyperactivity and anxiety disorders. J Am Acad Child Adolesc Psychiatry 44(5):418-427. https://doi.org/10.1097/01.chi. 0000155320.52322 .37

4. Achenbach TM (2000a) CBCL 11/2 - 5 Child Behavior Checklist 11/2 - 5. Hogrefe, Göttingen (DeutscheFassung)

5. Achenbach TM (2000b) C-TRF 11/2 - 5 Caregiver-Teacher Report Form. Hogrefe, Göttingen (Deutsche Fassung)

6. Aghaei M, Hosna Janjani, Fatemeh Yousefian, Akram J, Yunesian M (2019) Association between ambient gaseous and particulate air pollutants and attention deficit hyperactivity disorder (ADHD) in children. a systematic review. Environ Res 173:135-156. https://doi.org/10.1016/j.envres. 2019.03.030

7. Albajara Sáenz A, Villemonteix T, Massat (2018) Structural and functional neuroimaging in attention-deficit/hyperactivity disorder. Dev Med Child Neurol 61(4):399-405. https://doi.org/10. 1111/dmcn. 14050

8. Albrecht B, Uebel von Sandersleben H, Gevensleben $\mathrm{H}$, Rothenberger A (2015) Pathophysiology of ADHD and associated problems-starting points for NF interventions? Front Hum Neurosci 9(359):1-14. https://doi.org/10.3389/fnhum. 2015.00359

9. Alderson RM, Kasper LJ, Hudec KL, Patros CH (2013) Attention-deficit/hyperactivity disorder (ADHD) and working memory in adults: a meta-analytic review. Neuropsychology 27(3):2878-2302

10. American Psychiatric Association (2013) Diagnostic and Statistical Manual of Mental Disorders, 5. Aufl. DSM-5. American Psychiatric Publishing Arlington

11. American Academy of Pediatrics, Section On Complementary And Integrative Medicine and Council on Children with Disabilities (2012) Sensory integration therapies for children with developmental and behavioral disorders. Pediatrics 129(6):1186-1189

12. Angold A, Costello J, Erkanli A (1999) Comorbidity. J Child Psychol Psychiatry 40(1):57-87

13. Anheyer D, Lauche R, Schumann D, Dobos G, Cramer H (2017) Herbal medicines in children with attention deficit hyperactivity disorder (adhd): A systematic review. Complement Ther Med 30:14-23. https://doi.org/10.1016/j.ctim.2016.11. 004

14. Arnett AB, MacDonald B, Pennington BF (2013) Cognitive and behavioral indicators of $A D H D$ symptoms prior to school age. J Child Psychol Psychiatry 54(12):1284-1294. https://doi.org/10. 1111/jcpp.12104

15. Arns M, Heinrich H, Strehl U (2014) Evaluation of neurofeedback in ADHD: the long and winding road. Biol Psychol 95:108-115

16. Arnsten AF, Scahill L, Findling RL (2007) Alpha-2 adrenergic receptor agonists for the treatment of attention-deficit/hyperactivity disorder: Emerging concepts from new data. J Child Adolesc Psychopharmacol 17(4):393-406

17. Aschenbrenner S, Tucha O, Lange KW (2001) Regensburger Wortflüssigkeits-Test. Hogrefe, Göttingen

18. Aston-Jones G, Bloom FE (1981) Norepinephrine containing locus coeruleus neurons in behaving rats exhibit pronounced responses to non-noxious environmental stimuli. J Neurosci 1:887-900

19. Avni E, Ben-Itzchak E, Zachor DA (2018) The presence of co-morbid ADHD and anxiety symptoms in autism spectrum disorder: Clinical presentation and predictors. Front Psychiatry 9(717):1-12. https://doi.org/10.3389/fpsyt.2018. 00717

20. Bader A, Adesman A (2012) Complementary and alternative therapies for children and adolescents with ADHD. Curr Opin Pediatr 24(6):760-769

21. Bakley RA (Hrsg) (2015) Attention-deficit hyperactivity disorder. A handbook for diagnosis and treatment, 4. Aufl. Guilford, New York-London

22. Banaschewski T, Coghill D, Santosh P, Zuddas A, Asherson P, Buitelaar J, Danckaerts M, Döpfner M Faraone SV, Rothenberger A, Sergeant J, Steinhausen HC, Sonuga-Barke EJ, Taylor E (2006) Long-acting medications for the hyperkinetic disorders. A systematic review and European treatment guideline. Eur Child Adolesc Psychiatry 15(8):476-495

23. Bangasser DA, Eck SR, Ordoñes Sanchez E (2018) Sex differences in stress reactivity in arousal and attention systems. Neuropsychopharmacology 44(1):129-139. https://doi.org/10.1038/s41386018-0137-2

24. Bar Lambez, Harwood-Gross A, Zion Golumbic E, Rassovsky Y (2020) Non-pharmacological interventions for cognitive difficulties in ADHD: a systematic review and meta-analysis. J Psychiatr Res 120:40-55. https://doi.org/10.1016/j. jpsychires.2019.10.007

25. Bar S, Milanaik R, Adesman A (2016) Long-term neurodevelopmental benefits of breastfeeding. Curr Opin Pediatr 28(4):559-566. https://doi.org/ 10.1097/mop.0000000000000389

26. Barkley RA (1997) Behavioral inhibition, sustained attention, and executive functions: constructing a unifying theory of ADHD. Psychol Bull 121(1):65-94

27. Barkley RA (2008) Global issues related to the im pact of untreated attention-deficit/hyperactivity disorder from childhood to young adulthood. Postgrad Med 120(3):48-59. https://doi.org/10. 3810/pgm.2008.09.1907

28. Barkley RA, McMurray MB, Edelbrock CS, Robbins K (1990) Side effects of methylphenidate in children with attention deficit hyperactivity disorder: a systemic, placebo-controlled evaluation. Pediatrics 86(2):184-192

29. Bartels A, Zeki S (2005) Brain dynamics during natural viewing conditions-a new guide for mapping connectivity in vivo. Neuroimage 24:339-349

30. Bäumler G (1985) Farbe-Wort-Interferenztest [Color-Word-Interference Test]. Hogrefe, Göttingen

31. Baweja R, Mattison RE, Waxmonsky JG (2015) Impact of attention-deficit hyperactivity disorder on school performance: what are the effects of medication? Paediatric Drugs 17(6):459-477. https://doi.org/10.1007/s40272-015-0144-2

32. Beard JL, Connor JR (2003) Iron status and neural functioning. Annu Rev Nutr 23:41-58

33. Beck AT, Steer RA, Brown GK, Hautzinger M, Keller F, Kühner C (2006) BDI-II Beck-Depressionsinventar. Hogrefe, Göttingen

34. Ben-Sasson A, Carter AS, Briggs-Gowan MJ (2009) Sensory over-responsivity in elementary school: prevalence and social-emotional correlates. JAbnorm Child Psychol 37:705-716

35. Besag F,AldenkampA, Caplan R, Dunn DW, GobbiG, Sillanpää M (2016) Psychiatric and behavioural disorders in children with epilepsy (ilae task force report): Epidemiology of psychiatric/behavioural disorder in children with epilepsy. Epileptic Disord 18(s1):s2-s7 
36. Biederman J, Ball SW, Monuteaux MC, Mick E, Spencer TJ, Mc-Creary M, Cote M, Faraone SV (2008) Newinsights into the co-morbidity between ADHD and major depression in adolescent and young adult females. J Am Acad Child Adolesc Psychiatry 47:426-234

37. Biederman J, Faraone SV, Mick E, Lelon E (1995) Psychiatric comorbidity among referred juveniles with major depression: fact or artifact? J Am Acad Child Adolesc Psychiatry 34:579-590

38. Biederman J, Faraone SV, Mick E, Williamson S, Wilens TE, Spencer TJ, Weber W, Jetton J, Kraus I, Pert J, Zallen B (1999) Clinical correlates of ADHD in females: findings from a large group of girls ascertained from pediatric and psychiatric referral sources. J Am Acad Child Adolesc Psychiatry 38(8):768-770

39. Biederman J, Faraone SV, Milbeger S, Garcia Jetton J, Chen L, Mick E, Greene RW, Russel RL (1996) Is childhood oppositional defiant disorder a precursor to adolescent conduct disorder? Findings from a four-year follow-up study of children with ADHD. J Am Acad Child Adolesc Psychiatry 35(9):1193-1204. https://doi.org/10. 1097/00004583-199609000-00017

40. Biederman J, Melmed RD, Patel A, McBurnett K, Konow J, Lyne A, Scherer N, SPD503 Study Group (2008) A randomized, double-blind, placebocontrolled study of guanfacine extended release in children and adolescents with attention-deficit/ hyperactivity disorder. Pediatrics 121(1):e73-e84. https://doi.org/10.1542/peds.2006-3695

41. Biederman J, Milberger S, Faraone SV, Kiely K, Guite J, MickE, Ablon S, Warburton R, Reed E (1995) Family-environment risk factors for attentiondeficit hyperactivity disorder. A test of Rutter's indicators of adversity. Arch Gen Psychiatry 52(6):464-470

42. Biederman J, Petty $C R$, Fried $R$, Black $S$, Faneuil AAED, Seidman LJ, Faraone SV (2008) Discordance between psychometric testing and questionnaire-based definitions of executive function deficits in individuals with ADHD. J Atten Disord 12(1):92-102. https://doi.org/10.1177/ 1087054707305111

43. Biederman J, Wilens T, MickE, Spencer T, Faraone SV (1999) Pharmacotherapy of attention-deficit/ hyperactivity disorder reduces risk for substance use disorder. Pediatrics 104(2):e20

44. Bijlenga D, Vollebregt MA, Kooij JJS, Arns M (2019) The role of the circadian system in the etiology and pathophysiology of ADHD: time to redefine ADHD? Atten Deficit Hyperact Disord 11(1):5-19. https:// doi.org/10.1007/s12402-018-0271-z

45. Bloch MH, Panza KE, Landeros-Weisenberger A Leckman JF (2009) Meta-analysis: treatment of attention-deficit/hyperactivity disorder in children with comorbid tic disorders. J Am Acad Child Adolesc Psychiatry 48(9):884-893

46. Bor W, Sanders MR, Markie-Dadds C (2002) J Abnorm Child Psychol 30(6):571-587. https:// doi.org/10.1023/a:1020807613155

47. Bowie CR, Harvey PD (2006) Administration and interpretation of the trail making test. Nat Protoc 1(5):2277-2281

48. Braun S, Zeidler J, Linder R, Engel S, Verheyen F, Greiner W (2013) Treatment costs of attention deficit hyperactivity disorder in Germany. Eur J Health Econ 14(6):939-945

49. Brown JT, Bishop JR, Sangkuhl K, Nurmi EL, Mueller DJ, Dinh JC, Gaedigk A, Klein TE, Caudle KE, McCracken JT, de Leon J, Leeder JS (2019) Clinical pharmacogenetics implementation consortium guideline for cytochrome p450 (cyp)2d6 genotype and atomoxetine therapy. Int J Clin Pharmacol The 106(1):94-102.https://doi.org/10.1002/cpt.1409

50. Brown KA, Samuel S, Patel DR (2018) Pharmacologic management of attention deficit hyperactivity disorder in children and adolescents: a review for practitioners. Transl Ational Pediatr 7(1):36-47. https://doi.org/10.21037/tp.2017.08.02

51. Bruni O, Alonso-Alconada D, Besag F, Biran V Braam W, Cortese S, Moavero R, Parisi P, Smits M, Van der Heijden K, Curatolo P (2015) Current role of melatonin in pediatric neurology: clinical recommendations. Eur J Paediatr Neurol 19(2):122 https://doi.org/10.1016/j.ejpn.2014.12.007

52. Butler SF, Arredondo DE, McCloskey V (1995) Affective comobidity in children and adolescents with attention deficit hyperactivity disorder. Ann of Clinical Psychiatry 7:51-55

53. Caci $H$, Asherson P, Donfrancesco R, Faraone SV Hervas A, Fitzgerald M, Döpfner M (2014) Daily life impairments associated with childhood/ adolescent attention-deficit/hyperactivity disorder as recalled by adults: results from the European Lifetime Impairment Survey. CNS Spectr. https:// doi.org/10.1017/S1092852914000078

54. Caito S, Aschner M (2017) Developmental neurotoxicity oflead.In:Advances in neurobiology. Springer, Berlin Heidelberg, S3-12 https://doi.org/ 10.1007/978-3-319-60189-2 1

55. Calvo N, Benjamin L, Serrat L, Pérez-Rodríguez V, Andión Ò, Ramos-Quiroga JA, Ferrer M (2020) The role of environmental influences in the complex relationship between borderline personality disorder and attention-deficit/hyperactivity disorder: review of recent findings. bord personal disord emot dysregul. https://doi.org/10.1186/s40479019-0118-z

56. Caye A, Spadini AV, Karam RG, GrevetEH, RovarisDL, Bau CHD, Rohde LA, Kieling C (2016) Predictors of persistence of $A D H D$ into adulthood: a systematic review of the literature and meta-analysis. Eur Child 25(11):1151-1159. https://doi.org/10.1007/ s00787-016-0831-8

57. Cenit MC, Campillo Nuevo I, Codoñer-Franch $P$ Dinan TG, Sanz Y (2017) Gut microbiota and attention deficit hyperactivity disorder: new perspectives for a challenging condition. Eur Child Adolesc Psychiatry 26(9):1081-1092. https://doi. org/10.1007/s00787-017-0969-z

58. Ceranoglu TA (2018) Inattention to problematic media use habits. Child Adolesc Psychiatr Clin N Am 27(2):183-191. https://doi.org/10.1016/j.chc. 2017.11.009

59. César Cagigal, Tánia S, Jesus M, Silva C (2019) Does diet affect the symptoms of ADHD? CPB 20(2):130-136. https://doi.org/10.2174/ 1389201019666180925140733

60. Chan E, Fogler JM, Hammerness PG (2016) Treatment of attention-deficit/hyperactivity disorder in adolescents: a systematic review. JAMA 315(18):1997-2008. https://doi.org/10.1001/ jama.2016.5453

61. Chang Z, Ghirardi L, Quinn PD, Asherson P, D'Onofrio BM, Larsson H (2019) Risks and benefits of attention-deficit/hyperactivitydisorder medication on behavioral and neuropsychiatric outcomes: a qualitative review of pharmacoepidemiology studies using linked prescription databases. Bio Psychiatry. https://doi.org/10.1016/j.biopsych. 2019.04.009

62. Childress A (2017) The safety of extended-release drug formulations for the treatment of adhd. Expert Opin Drug Saf 16(5):603-615. https://doi. org/10.1080/14740338.2017.1317344
63. Childress AC Sallee FR (2014) Attention-deficit/ hyperactivity disorder with inadequate respons to stimulants: approaches to management. CNS Drugs 28(2):121-129

64. Childress AC, Sallee FR (2015) Emotional lability in patients with attention-deficit/hyperactivity disorder: impact of pharmacotherapy. CNS Drugs 29(8):683-693. https://doi.org/10.1007/s40263015-0264-9

65. Childress AC, Stark JG (2018) Diagnosis and treatment of attention-deficit/hyperactivity disorde in preschool-aged children. J Child Adolesc Psychopharmacol 28(9):606-614. https://doi.org/10. 1089/cap.2018.0057

66. Chin W-C, Huang Y-S, Chou Y-H, Wang C-H, Chen K-T, Fu Hsu J, Hsu S-C (2018) Subjective and objective assessments of sleep problems in children with attention deficit/hyperactivity disorder and the effects of methylphenidate treatment. Biomed J 41(6):356-363. https://doi. org/10.1016/j.bj.2018.10.004

67. Chiyoko Akutagava-Martins G, Rohde LA, Hutz MH (2016) Genetics of attention-deficit/ hyperactivity disorder: an update. Expert Rev Neurother 16(2):145-156. https://doi.org/10.1586/ 14737175.2016.1130626

68. Christiansen L, Beck MM, Bilenberg N, Wienecke J, Astrup A, Lundbye-Jensen J (2019) Effects of exercise on cognitive performance in children and adolescents with ADHD: potential mechanisms and evidence-based recommendations. JCM 8(6):841.https://doi.org/10.3390/jcm8060841

69. Chronis-Tuscano A, Molina BSG, Pelham WE, Applegate B, Dahlke A, Overmyer M, Lahey BB (2010) Very early predictors of adolescent depression and suicide attempts in children with attention-deficit/hyperactivity disorder. JAMA Psychiatry 67(10):1044-1051

70. Ciro Marangoni, De Chiara L, Faedda GL (2015) Bipolar disorder and ADHD: comorbidity and diagnostic distinctions. Curr Psychiatry Rep. https://doi.org/10.1007/s11920-015-0604-y

71. Clark B, Bélanger SA (2018) ADHD in children and youth: Part 3-Assessment and treatment with comorbid ASD, ID, or prematurity. Paediatr Child Health. https://doi.org/10.1093/pch/pxy111

72. Clemow DB, Bushe CJ (2015) Atomoxetine in patients with ADHD: A clinical and pharmacological review of the onset, trajectory, duration of response and implications for patients. J Psychopharmacol 29(12):1221-1230. https://doi.org/10 $1177 / 0269881115602489$

73. Coates J, Taylor JA, Sayal K (2015) Parenting interventions for adhd: a systematic literature review and meta-analysis. J Atten Disord 19(10):831-843. https://doi.org/10.1177/1087054714535952

74. Coghill D, Banaschewski T, Zuddas A, Pelaz A, Gagliano A, Döpfner M (2013) Long-acting methylphenidate formulations in the treatment of attention-deficit/hyperactivity disorder: a systematic review of head-to-head studies. BMC Psychiatry 13:237

75. Coghill DR, Banaschewski T, Soutullo C, Cottingham MG, Zuddas A (2017) Systematic review of quality of life and functional outcomes in randomized placebo-controlled studies of medications for attention-deficit/hyperactivity disorder. Eur Child Adolesc Psychiatry 26(11):1283-1307. https://doi. org/10.1007/s00787-017-0986-y

76. Connell AM, Dishion TJ, Yasul M, Kavanagh K (2007) An adaptive approach to family intervention: linking engagement in family-centered intervention to reductions in adolescent problem behavior. JConsult Clin Psychol 75:568-579 
77. ConnorDF (2005a) Stimulants. In: Attention-deficit hyperactivity disorder. A handbook for diagnosis and treatment, 3. Aufl. Guilford, New York, $S$ 608-647

78. Connor DF (2005b) Other medications. In: Attention-deficit hyperactivity disorder. A handbook for diagnosis and treatment, 3. Aufl. Guilford, New York, S658-677

79. Connor DF, Carlson GA, Kiki DC, Daniolos PT, Ferziger R, Findling RL, Hutchinson JG, Malone RP, Halperin JM, Plattner B, Post RM, Reynolds DL, Rogers KM, Saxena K, Steiner H, Stanford/Howard/ AACAP Workgroup on Juvenile Impulsivity and Aggression (2006) Juvenile maladaptive aggression: A review of prevention, treatment, and service configuration and a proposed research agenda. JClin Psychiatry 67(5):808-820

80. Cooper RE, Tye C, Kuntsi J, Vassos E, Asherson P (2016) The effect of omega-3 polyunsaturated fatty acid supplementation on emotional dysregulation, oppositional behaviour and conduct problems in ADHD: A systematic review and metaanalysis. J Affect Disord 190:474-482. https://doi. org/10.1016/j.jad.2015.09.053

81. Copeland W, Shanahan L, Costello EJ, Angold A (2009) Configurations of common childhood psychosocial risk factors. J Child Psychol Psychiatry 50(4):451-459. https://doi.org/10.1111/j.14697610.2008.02005.x

82. Cording C, GaebelW, Spengler A, StieglitzRD (1995) Die neue psychiatrische Basisdokumentation. Eine Empfehlung der DGPPN zur Qualitätssicherung im (teil-)stationären Bereich. Spektrum Psychiatr Nervenheilkd 24(1):3-41

83. Cortese S, Coghill D (2018) Twenty years of research on attention-deficit/hyperactivity disorder (ADHD): looking back, looking forward. Evid Based Ment Health 21(4):173-176. https://doi.org/10. 1136/ebmental-2018-300050

84. Cortese S, Ferrin M, Brandeis D, Buitelaar J, Daley D, Dittmann RW, Holtmann M, Santosh $P$ Stevenson J, Stringaris A, Zuddas A, SonugaBarke EJS, the European ADHD Guidelines Group (EAGG) (2015) Cognitive training for attentiondeficit/hyperactivity disorder: Meta-analysis of clinical and neuropsychological outcomes from randomized controlled trials. J Am Acad Child AdolescPsychiatry 54(3):164-174.https://doi.org/ 10.1016/j.jaac.2014.12.010

85. Cutler AJ, Mattingly GW (2017) Beyond the pill: new medication delivery options for adhd. CNS Spectr 22(6):463-474. https://doi.org/10.1017/ s1092852916000936

86. Daley D, Van Der Oord S, Ferrin M, Cortese S, Danckaerts $M$, Doepfner $M$, Van den Hoofdakker BJ, Coghill D, Thompson M, Asherson P, Banaschewski T, Brandeis D, Buitelaar J, Dittmann RW, Hollis C, Holtmann M, Konofal E, Lecendreux M, Rothenberger A, Paramala Santosh, Simonoff E, Soutullo C, Steinhausen HC, Stringaris A, Taylor E, Wong ICK, Zuddas A, Sonuga-Barke EJ (2017) Practitioner review: Current best practice in the use of parent training and other behavioural interventions in the treatment of children and adolescents with attention deficit hyperactivity disorder. J Child Psychol Psychiatry 59(9):932-947. https://doi.org/ 10.1111/jcpp. 12825

87. Danckaerts M, Sonuga-Barke EJS, Banaschewski T, Buitelaar J, Döpfner M, Hollis C, Santosh P, Rothenberger A, Sergeant J, Steinhausen H-C, Taylor E, Zuddas A, Coghill D (2010) The quality of life of children with attention deficit/hyperactivity disorder: a systematic review. Eur Child Adolesc
Psychiatry 19:83-105. https://doi.org/10.1007/ s00787-009-0046-3

88. Dark C, Homman-Ludiye J, Bryson-Richardson RJ (2018) The role of ADHD associated genes in neurodevelopment. Dev Biol 438(2):69-83. https://doi.org/10.1016/j.ydbio.2018.03.023

89. Daseking M, Petermann F (2013) BRIEF-P Verhaltensinventar zur Beurteilung exekutiver Funktionen für das Kindergartenalter. Hogrefe, Göttingen

90. Daseking M, Petermann F, Danielsson J (2009) KET-KID Kognitiver Entwicklungstest für das Kindergartenalter. Hogrefe, Göttingen

91. Daviss WB (2008) A review of co-morbid depression in pediatric ADHD: Etiologies, phenomenology, and treatment. J Child Adolesc Psychopharmacol 18(6):565-571

92. Decker MJ, Rye DB (2002) Neonatal intermittent hypoxia impairs dopamine signaling and executive functioning. Sleep Breath 6:205-210

93. Del-Ponte B, Callo Quinte G, Suélen C, Grellert M, InáSS(2019) Dietary patterns and attention deficit/ hyperactivity disorder (ADHD): a systematic review and meta-analysis. J Affect Disord 252:160-173. https://doi.org/10.1016/j.jad.2019.04.061

94. Deutsche Gesellschaft fü Kinder- und Jugendpsychiatrie, Deutsche Gesellschaft für Psychiatrie und Psychotherapie, Psychosomatik und Nervenheilkunde, and Deutsche Gesellschaft für Sozialpädiatrie und Jugendmedizin. Kurzfassung der interdisziplinären evidenz- und konsensbasierten (S3) Leitlinie „Aufmerksamkeitsdefizit-/ Hyperaktivitätsstörung (ADHS) im Kindes-, Jugend- und Erwachsenenalter". AWMF-Registernummer 028045 [Interdisciplinary evidence and consensus based guideline, ADHD in children, adolescents and adults]. https://www.awmf.org/uploads/tx szleitlinien/028-045k_S3 ADHS 2018-06.pdf, 2017.

95. Dong T, Hu W, Zhou X, Lin H, Lan L, Hang B, Lv W, Geng Q, Xia Y (2018) Prenatal exposure to maternal smoking during pregnancy and attention-deficit/ hyperactivity disorder in offspring: a metaanalysis. Reprod Toxicol 76:63-70. https://doi.org/ 10.1016/j.reprotox.2017.12.010

96. DonzelliG, Carducci A, Llopis-Gonzalez A, Verani M Llopis-Morales A, Cioni L, Morales-Suárez-Varela M (2019) The association between lead and attention-deficit/hyperactivity disorder: a systematic review. IJERPH 16(3):382. https://doi.org/10.3390/ ijerph 16030382

97. Döpfner M, Lehmkuhl G (2003) DiagnostikSystem für psychische Störungen im Kindes- und Jugendalter nach ICD-10 und DSM-IV (DISYPS-KJ). Huber, Bern

98. Döpfner M, Görtz-Dorten A, Lehmkuhl G, Breuer D, Goletz H (2008) DISYPS-II Diagnostik-System für psychische Störungen nach ICD-10 undDSM-IV für Kinder und Jugendliche-II. Hogrefe, Göttingen

99. Döpfner M, Schnabel M, Goletz H, Ollendick TH (2006) PHOKI Phobiefragebogen für Kinder und Jugendliche. Hogrefe, Göttingen

100. Döpfner M, Schürmann S, Frölich J (2002) Therapieprogramm für Kinder mit hyperkinetischem und oppositionellem Problemverhalten [Curative program for children with hyperkinetic and oppositional defiant problem behavior], 3. Aufl. Beltz, Weinheim

101. Döpfner M, Schürmann S, Frölich J (2007) Therapieprogramm für Kinder mit hyperkinetischem und oppositionellem Problemverhalten (THOP), 4. Aufl. Beltz, Weinheim

102. Döpfner M, Schürmann S, Lehmkuhl G (2011) Wackelpeter und Trotzkopf. Hilfen für Eltern bei hyperkinetischem und oppositionellem Verhalten 4. Aufl. Beltz, Weinheim

103. Drechsler R, Steinhausen HC (2013) BRIEF Verhaltensiventar zur Beurteilung exekutiver Funktionen. Hogrefe, Göttingen

104. DuPaul GJ, Reid R, Anastopoulos AD, Lambert MC, Watkins MW, Power TJ (2016) Parent and teacher ratings of attention-deficit/hyperactivity disorder symptoms: factor structure and normative data. Psychol Assess 28(2):214-225. https://doi.org/10. 1037/pas0000166

105. Dórea JG (2019) Environmental exposure to low-level lead $(\mathrm{Pb})$ co-occurring with othe neurotoxicants in early life and neurodevelopment of children. Environ Res. https://doi.org/10.1016/j. envres.2019.108641

106. Fairchild G, Hawes DJ, Frick PJ, Copeland WE Odgers CL, Franke B, Freitag CM, De Brito SA (2019) Conduct disorder. Nat Rev Dis Primers. https://doi. org/10.1038/s41572-019-0095-y

107. Faraone SV (2018) The pharmacology of amphet amine and methylphenidate: relevance to the neurobiology of attention-deficit/hyperactivity disorder and other psychiatric comorbidities. Neurosci Biobehav Rev 87:255-270. https://doi. org/10.1016/j.neubiorev.2018.02.001

108. Faraone SV, Biederman J (1997) Do attention deficit hyperactivity disorder and major depression share familial risk factors? J Nerv Ment Dis 185:533-541

109. Faraone SV, Doyle AE (2001) The nature and heritability of attention deficit/ hyperactivity disorder. Child Adolesc Psychiatr Clin N Am 10:299-316

110. Faraone SV, Doyle AE, Mick E, Biederman J (2001) Meta-analysis of the association between the 7-repeat allele of the dopamine $\mathrm{d}(4)$ receptor gene and attention deficit hyperactivity disorder. Am J Psychiatry 158:1052-1057

111. Faraone SV, Rostain AL, Blader J, Busch $B$ Childress AC, Connor DF, Newcorn JH (2019) Practitioner review: emotional dysregulation in attention-deficit/hyperactivity disorder - implications for clinical recognition and intervention. J Child Psychol Psychiatry 60(2):133-150. https:// doi.org/10.1111/jcpp.12899

112. Fateme Samea, Solmaz Soluki, Vahid Nejati, Mojtaba Zarei, Samuele Cortese, Eickhoff SB, Masoud Tahmasian, Eickhoff CR (2019) Brain alterations in children/adolescents with ADHD revisited: a neuroimaging meta-analysis of 96 structural and functional studies. Neurosci Biobehav Rev 100:1-8. https://doi.org/10.1016/j. neubiorev.2019.02.011

113. Feldman ME, Charach A, Belanger SA (2018) Adhd in children and youth: part 2-treatment. Paediat Child Health 23(7):462-472. https://doi.org/10. 1093/pch/pxy113

114. Findling RL, McBurnett $K$, White $C$, Youcha $S$ (2014) Guanfacine extended release adjunctive to a psychostimulant in the treatment of comorbid oppositional symptoms in children and adolescents with attention-deficit/hyperactivity disorder. J Child Adolesc Psychopharmacol 24(5):245-252

115. Fischman S, Kuffler DP, Bloch C (2014) Disordered sleep as a cause of attention deficit/hyperactivity disorder. Clin Pediatr (Phila) 54(8):713-722. https://doi.org/10.1177/0009922814548673

116. Fishman PA, Stang PE, Hogue SL (2007) Impact of co-morbid attention deficit disorder on the direct medical costs of treating adults with depression in managed care. JClin Psychiatry 68:248-253

117. Frampton JE (2018) Lisdexamfetamine dimesylate: A review in paediatric ADHD. Drugs 
78(10):1025-1036. https://doi.org/10.1007/ s40265-018-0936-0

118. Franke B, Michelini G, Asherson P, Banaschewski T, Bilbow A, Buitelaar JK, Cormand B, Faraone SV, Ginsberg Y, Haavik J, Kuntsi J, Larsson H, Lesch K-P, Ramos-Quiroga JA, Réthelyi JM, Ribases M, Reif A (2018) Live fast, die young? a review on the developmental trajectories of ADHD across the lifespan. Eur Neuropsychopharmacol. https://doi. org/10.1016/j.euroneuro.2018.08.001

119. Franz AP, Bolat GU, Bolat $H$, Matijasevich A, Iná SS, Silveira RC, Soibelmann Procianoy $R$, Rohde LA, Moreira-Maia CR (2017) Attentiondeficit/hyperactivity disorder and very preterm/ very low birth weight: a meta-analysis. Pediatrics 141(1):e20171645.https://doi.org/10.1542/peds. 2017-1645

120. Freeman RD, Tourette Syndrome International Database Consortium (2007) Tic disorders and ADHD: answers from a world-wide clinical dataset on Tourette syndrome. EurChild AdolescPsychiatry (Suppl 1):16-23. https://doi.org/10.1007/s00787007-1003-7

121. Freitag CM, Hänig S, Schneider A, Seitz C, Palmason H, Retz W, Meyer J (2012) Biological and psychosocial environmental risk factors influence symptom severity and psychiatric comorbidity in children with ADHD. J Neural Transm 119:81-94

122. Fritz A, Hussy W (2000) Zoo-Spiel. Ein Test zur Planungsfähigkeit bei Grundschulkindern. Hogrefe, Göttingen

123. Frodl T, Skokauskas N (2011) Meta-analysis of structural MRI studies in children and adults with attention deficit hyperactivity disorder indicates treatment effects. Acta Psychiatr Scand 125(2):114-126. https://doi.org/10.1111/j.16000447.2011.01786.x

124. Frölich J, Banaschewski T, Spanagel R, Döpfner M, Lehmkuhl G (2012) Die medikamentöse Behandlung der Aufmerksamkeitsdefizit-Hyperaktivitätsstörung im Kindes- und Jugendalter mit Amphetaminpräparaten.Z Kinder Jugendpsychiatr Psychother 40(5):287-300

125. De La Fuente A, Xia S, Branch C, Li X (2013) A review of attention-deficit/hyperactivity disorder from the perspective of brain networks. Front Hum Neurosci 7:192

126. Fuermaier ABM, Hüpen P, De Vries SM, Müller M, Kok Janneke Koerts FM, Heutink J, Tucha L, Gerlach M, Tucha $O$ (2017) Perception in attention deficit hyperactivity disorder. Atten Deficit Hyperact Disord 10(1):21-47. https://doi.org/10.1007/ s12402-017-0230-0

127. Galloway H, Newman E (2017) Is there a difference between child self-ratings and parent proxyratings of the quality of life of children with a diagnosis of attention-deficit hyperactivity disorder (ADHD)? a systematic review of the literature. Atten Defic Hyperact Disord 9:11-29. https://doi.org/10.1007/s12402-016-0210-9

128. Gardner DM, Gerdes AC (2015) A review of peer relationships and friendships in youth with ADHD. J Atten Disord 19(10):844-855. https://doi.org/10 $1177 / 1087054713501552$

129. Gediga G, Schöttke H (2004) Osnabrücker Turm von Hanoi. Hogrefe, Göttingen

130. Geller B, Zimerman B, Williams M, DelBello MP, Frazier J, Beringer $L$ (2002) Phenomenology of prepubertal and early adolescent bipolar disorder: Examples of elated mood, grandiose behaviors, decreased need for sleep, racing thoughts, and hypersexuality. J Child Adolesc Psychopharmacol 12(1):3-9
131. Geller B, Zimmerman B, Williams M, Bolhofner K, Craney JL (2001) Bipolar disorder at prospective follow-up of adults who had prepubertal major depressive disorder. Am J Psychiatry 158(1):125-127

132. Gerlach M, Banaschewski T, Coghill D, Rohde LA, Romanos M (2017) What are the benefits of methylphenidate as a treatment for children and adolescents with attention-deficit/hyperactivity disorder? Atten Deficit Hyperact Disord 9(1):1-3. https://doi.org/10.1007/s12402-017-0220-2

133. Gill M, Daly G, Heron S, Hawi Z, Fitzgerald M (1997) Confirmation of association between attention deficit hyperactivity disorder and a dopamine transporter polymorphism. Mol Psychiatry 2(4):311-313

134. Gioia GA, Isquith PK, Kenworthy L, Barton R (2002) Profiles of everyday executive function in acquired and developemental disorders. Child Neuropsychol 8(2):121-137

135. Gizer IR, Ficks C, Waldman ID (2009) Candidate gene studies of ADHD: a meta-analytic review. Hum Genet 126:51-90

136. Goldman LS, Genel M, Bezman RJ, Slanetz PJ (1998) Diagnosis and treatment of attention-deficit/ hyperactivity disorder in children and adolescents. Council on Scientific Affairs, American Medical Association. JAMA 279(14):1100-1107

137. Goth K, Schmeck K (2009) JTCl junior temperament und charakter inventar. Hogrefe, Göttingen

138. Grant DA, Berg EA (1993) WCST ${ }^{\circledR}$ wisconsin card sorting test. Hogrefe, Göttingen

139. Gray C, Climie EA (2016) Children with attention deficit/hyperactivity disorder and reading disability: a review of the efficacy of medication treatments. Front Psychol. https://doi.org/10. 3389/fpsyg.2016.00988

140. Greenhill LL, Pliszka S, Dulcan MK (2002) Practice parameter for the use of stimulant medications in the treatment of children, adolescents, and adults. J Am Acad Child Adolesc Psychiatry 41(2):26S-49S https://doi.org/10.1097/00004583-20020200100003

141. Grimm O, Kittel-Schneider S, Reif A (2018) Recent developments in the genetics of attentiondeficit hyperactivity disorder. Psychiatry Clin Neurosci 72(9):654-672. https://doi.org/10.1111/ pcn. 12673

142. Groenman AP, Janssen TWP, Oosterlaan J (2017) Childhood psychiatric disorders as risk factor fo subsequent substance abuse: a meta-analysis. J Am Acad Child Adolesc Psychiatry 56(7):556-569. https://doi.org/10.1016/j.jaac.2017.05.004

143. Guanfacine for adhd in children and adolescents. Drug and Therapeutics Bulletin, 54(5):56-60, 2016. ISSN 0012-6543. https://doi.org/10.1136/ dtb.2016.5.0402.

144. Hahn-Markowitz J, Manor J, Maeir A (2011) Effectiveness of cognitive- functional (cog-fun) intervention with children with attention deficit hyperactivity disorder: a pilot study. Am J Occup Ther 65(4):384-392

145. Hall CL, Valentine $A Z$, Groom MJ, Walker GM, Sayal K, Daley D, Hollis C (2016) The clinical utility of the continuous performance test and objective measures of activity for diagnosing and monitoring adhd in children: a systematic review. Eur Child AdolescPsychiatry 25(7):677-699.https://doi.org/ 10.1007/s00787-015-0798-x

146. Halperin JM, Marks DJ (2019) Practitioner review: assessment and treatment of preschool children with attention-deficit/hyperactivity disorder. J Child Psychol Psychiatry 60(9):930-943. https:// doi.org/10.1002/14651858.CD003018.pub3
147. Hanć T, Cortese S (2018) Attention deficit/ hyperactivity-disorder and obesity: a review and model of current hypotheses explaining their comorbidity. Neurosci Biobehav Rev 92:16-28. https://doi.org/10.1016/j.neubiorev.2018.05.017

148. Hawi Z, Cummins TDR, Tong J, Johnson B, Lau R, Samarrai W, Bellgrove MA (2015) The molecular genetic architecture of attention deficit hyperactivity disorder. Mol Psychiatry 20(3):289-297. https://doi.org/10.1038/mp.2014. 183

149. Hedley D, Uljarević M, Foley K-R, Richdale A, Trollor J (2018) Risk and protective factors underlying depression and suicidal ideation in autism spectrum disorder. Depress Anxiety 35(7):648-657.https://doi.org/10.1002/da.22759

150. Den Heijer AE, Groen $Y$, Tucha L, Fuermaier ABM Koerts J, Lange KW, Thome J, Tucha $O$ (2017) Sweat it out? the effects of physical exercise on cognition and behavior in children and adults with adhd: a systematic literature review. J Neural Transm 124(1):3-26. https://doi.org/10.1007/ s00702-016-1593-7

151. Helmstaedter C, Lendt M, Lux S (2001) VLMT Verbaler Lern- und Merkfähigkeitstest. Hogrefe, Göttingen

152. Hemmingsson H, Ólafsdóttir LB, Thóra Egilson S (2016) Agreements and disagreements between children and their parents in health-related assessments. Disabil Rehabil 39(11):1059-1072. https://doi.org/10.1080/09638288.2016.1189603

153. Herskovits EH, Megalooikonomou V, Davatzikos C, Chen A, Bryan RN, Gerring JP (1999) Is the spatial distribution of brain lesions associated with closed-head injury predictive of subsequent development of attention-deficit/hyperactivity disorder? Analysis with brain-image database. Radiology 213(2):389-394

154. Hinshaw SP (2018) Attention Deficit Hyperactivity Disorder (ADHD): Controversy, developmental mechanisms, and multiple levels of analysis. Annu Rev Clin Psychol 14:291-316. https://doi.org/10. 1146/annurev-clinpsy-050817-084917

155. Holbrook BD (2016) The effects of nicotine on human fetal development. Birth Defects Res Part C: Embryo Today Rev 108(2):181-192. https://doi. org/10.1002/bdrc.21128

156. Holland J, Sayal K (2018) Relative age and adhd symptoms, diagnosis and medication: a systematic review. Eur Child Adolesc Psychiatry. https://doi. org/10.1007/s00787-018-1229-6

157. Holmskov M, Storebø OJ, Moreira-Maia CR, Ramstad E, Løgstrup Magnusson F, Krogh HB, Groth C, Gillies D, Zwi M, Skoog M, Gluud C, Simonsen E (2017) Gastrointestinal adverse events during methylphenidate treatment of children and adolescents with attention deficit hyperactivity disorder: A systematic review with meta-analysis and trial sequential analysis of randomised clinical trials. PLOS ONE 12(6):e178187. https://doi.org/10. 1371/journal.pone.0178187

158. Hoza B, Martin CP, Pirog A, Shoulberg EK (2016) Using physical activity to manage ADHD symptoms: the state of the evidence. Curr Psychiatry Rep. https://doi.org/10.1007/s11920016-0749-3

159. Huang L, Wang $Y$, Zhang L, Zheng Z, Zhu T, Qu Y, Mu D (2017) Maternal smoking and attentiondeficit/hyperactivity disorder in offspring: a metaanalysis. Pediatrics 141(1):e20172465. https://doi. org/10.1002/14651858.CD003018.pub3

160. Huang X, Wang M, Zhang $Q$, Chen X, Wu J (2019) The role of glutamate receptors in attention-deficit/ hyperactivity disorder: from physiology to disease. 
Am J Med Genet 180(4):272-286. https://doi.org/ 10.1002/ajmg.b.32726

161. Hutchison SL, Ghuman JK, Ghuman HS, Karpov I, Schuster JM (2016) Efficacy of atomoxetine in the treatment of attention-deficit hyperactivity disorder in patients with common comorbidities in children, adolescents and adults: a review. Therapeutic Advances in 6(5):317-334. https:// doi.org/10.1177/2045125316647686

162. Jensen PS, Arnold LE, Swanson JM, Vitiello B, Abikoff HB, Greenhill LL, Hechtman L, Hinshaw SP, Pelham WE, Wells KC, Conners CK, Elliott GR, Epstein JN, Hoza B, March JS, Molina BS, Newcorn JH, Severe JB, Wigal T, Gibbons RD, Hur K (2007) 3-year follow-up of the NIMH MTA study. J Am Acad Child Adolesc Psychiatry 46(8):989-1002

163. Jensen PS, Martin D, Cantwell (1997) Comorbidity in ADHD: Implication for research practice and DSM-v. J Am Acad Child Adolesc Psychiatry 36(3):1065-1079. https://doi.org/10.1177/ 108705479700200307

164. Jones K, Daley D, Hutchings J, Bywater T, Eames C (2008) Efficacy of the incredible years programme as an early intervention for children with conduct problems and ADHD: long-term follow-up. Child Care Health Dev 34(3):380-390. https://doi.org/ 10.1111/j.1365-2214.2008.00817x

165. Kalberg WO, Buckley D, May PA, Hasken JM, Marais A-S, De Vries MM, Bezuidenhout $H$, Manning MA, Robinson LK, Adam MP, Hoyme DB, Parry CDH, Seedat Elliott SAJ, Hoyme HE (2019) Early-life pre-dictors of fetal alcohol spectrum disorders. Pediatrics 144(6):e20182141. https:// doi.org/10.1542/peds.2018-2141

166. Kastner-Koller U, Deimann P (2012) WET Wiener Entwicklungstest. Hogrefe, Göttingen

167. Kaufman AS, Kaufman NL, Melchers P (2014) KABC IIKaufman Assessment Battery for Children, 2. Aufl. Hogrefe, Göttingen

168. Kemper AR, Maslow GR, Hill S, Namdari B, LaPointe NMA, Goode AP, Coeytaux RR, Befus D, Kosinski AS, Bowen SE, McBroom AJ, Lallinger KR, Sanders GD (2018) Attention deficit hyperactivity disorder: diagnosis and treatment in children and adolescents AHRQ comparative effectiveness review no. 203. Agency for Healthcare Research and Quality, Rockville

169. Kenealy LE, Paltin I (2012) Executive functions in disruptive behavior disorders. In: Executive Function and Dysfunction. Cambridge University Press, New York, S93-100

170. Kent L, Doerry U, Hardy E, Parmar R, Gingell $K$ Hawi Z, Kirley A, Lowe N, Fitzgerald M, Gill M Craddock N (2002) Evidence that variation at the serotonin transporter gene influences susceptibility to attention deficit hyperactivity disorder (ADHD): analysis and pooled analysis. Mo Psychiatry 7(8):908-912

171. Khushmand Rajendran, Rindskopf D, O'Neill $S$ Marks DJ, Nomura Y, Halperin JM (2013) Neuropsychological functioning and severity of ADHD in early childhood: a four-year cross-lagged study. J Abnorm Psychol 122(4):1179-1188

172. Killeen PR, Russell VA, Sergeant JA (2013) A behavioral neuroenergetics theory of ADHD. Neurosci Biobehav Rev 37:625-657

173. King RA (1997) Practice parameters for the psychiatric assessment of children and adolescents. J Am Acad Child Adolesc Psychiatry 36:4S-20S

174. KiserDP, Rivero O, Lesch K-P (2015) Annual research review: The (epi)genetics of neurodevelopmental disorders in the era of whole-genome sequencing - unveiling the dark matter. J Child Psychol
Psychiatry 56(3):278-295. https://doi.org/10. $1111 /$ jcpp.12392

175. Kok FM, Groen Y, Fuermaier AB, Tucha O (2016) Problematic peer functioning in girls with ADHD: a systematic literature review. PLoS One 11(11):e165119. https://doi.org/10.1371/journal. pone. 0165119

176. Konrad K, Eickhoff SB (2010) Is the ADHD brain wired differently? A review on structural and functional connectivity in attention deficit hyperactivity disorder. Hum Brain Mapp 31:904-916

177. Korkman M, KirkU, KempS(2007)A developmental NEuroPSYchiatric assessment (NEPSY $\left.{ }^{\circledR}\right)$, 2. Aufl. Pearson, Frankfurt

178. Krinzinger $\mathrm{H}$, Hall CL, Groom MJ, Ansari MT, Banaschewski T, Buitelaar JK, Carucci S, Coghill D, Danckaerts M, Dittmann RW, Falissard B, Garas P, Inglis SK, Kovshoff H, Puja Kochhar, McCarthy $\mathrm{S}$, Nagy P, Neubert A, Roberts S, Kapil Sayal, SonugaBarke E, Wong ICK, Jun Xia, Zuddas A, Hollis C, KonradK, Liddle EB (2019) Neurological and psychiatric adverse effects of long-term methylphenidate treatment in ADHD: A map of the current evidence. Neurosci Biobehav Rev 107:945-968. https://doi. org/10.1016/j.neubiorev.2019.09.023

179. Krowatschek D, Albrecht S, Krowatschek G (2004a) Marburger Konzentrationstraining für Schulkinder, 6. Aufl. Borgmann, Dortmund

180. KrowatschekD, Albrecht S, Krowatschek G (2004b) Marburger Konzentrationstraining (MKT) für Kindergarten- und Vorschulkinder. Borgmann, Dortmund

181. Kubinger KD (2009) AID 2 Adaptives Intelligenz Diagnostikum 2 (Version 2.2). Hogrefe, Göttingen

182. Kubinger KD, Holocher-Ertl S (2014) AID 3 Adaptives Intelligenz Diagnostikum 3. Hogrefe, Göttingen

183. Kurowski BG, Wade SL, Brown TM, Stancein T, Taylor HG (2013) Online problem-solving therapy for executive dysfunction after child traumatic brain injury. Pediatrics 132(1):e158-e166

184. Landau Z, Pinhas-Hamiel O (2019) Attention deficit/hyperactivity, the metabolic syndrome, and type 2 diabetes. Curr Diab Rep. https://doi.org/ 10.1007/s11892-019-1174- $x$

185. Lee PC, Niew WI, Yang HJ, Chen VC, Lin KC (2012) A meta-analysis of behavioral parent training for children with attention deficit hyperactivity disorder. Res Dev Disabil 33(6):2040-2049

186. Lee SS, Humphreys KL, Flory K, Liu R, Glass K (2011) Prospective association of childhood attention-deficit/hyperactivity disorder (ADHD) and substance use and abuse/ dependence: a metaanalytic review. Clin Psychol Rev 31(3):328-341

187. Levin RL, Rawana JS (2016) Attention-deficit/ hyperactivity disorder and eating disorders across the lifespan: a systematic review of the literature. Clin Psychol Rev 50:22-36. https://doi.org/10. 1016/j.cpr.2016.09.010

188. Lidzba K, Christiansen H, Drechlser R (2013) Conners Skalen zu Aufmerksamkeit und Verhalten -3. Hogrefe, Göttingen

189. Linton D, Barr AM, Honer WG, Procyshyn RM (2013) Antipsychotic and psychostimulant drug combination therapy in attention deficit/hyperactivity and disruptive behavior disorders: a systematic review of efficacy and tolerability. Curr Psychiatry Rep 15(5):355

190. Lis S, Baer N, Steinen Nosse C, Gallhofer B, Sammer G, Kirsch P (2010) Objective measurement of motor activity during cognitive performance in adults with attention deficit/hyperactivity disorder. Acta Psychiatr Scand 122:285-294
191. Liu X, Liu ZZ, Liu BP, Sun SH, Jia CX (2019) Associations of sleep problems with ADHD symptoms:findingsfrom the shandong adolescent behavior and health cohort(SABHC).Sleep. https:// doi.org/10.1093/sleep/zsz294

192. Llorente A (2001) Internal consistency, temporal stability, and reproducibility of individual index scores of the test of variables of attention in children with attention-deficit/hyperactivity disorder. Arch Clin Neuropsychol 16(6):535-546. https://doi.org/10.1016/s0887-6177(00)00065-2

193. Lochman JE, Powell NP, Boxmeyer $\mathrm{CL}_{\text {, Jimenez }}$ Camargo L (2011) Cognitive-behavioral therapy for externalizing disorders in children and adolescents. Child Adolesc Psychiatr Clin N Am 20(2):305-318

194. Loke H, Harley V, Lee J (2015) Biological factors underlying sex differences in neurological disorders. Int J Biochem Cell Biol 65:139-150. https://doi.org/ 10.1016/j.biocel.2015.05.024

195. van de Looij-Jansen PM, Goedhart AW, de Wilde EJ, Treffers PD (2011) Confirmatory factor analysis and factorial invariance analysis of the adolescent selfreport strengths and difficulties questionnaire: how important are method effects and minor factors? Br JClin Psychol 50(2):127-144

196. Loy JH, Merry SN, Hetrick SE, Stasiak K (2017) Atypical antipsychotics for disruptive behaviour disorders in children and youths. Cochrane Database Syst Rev 8(Cd008559):1-91. https://doi. org/10.1002/14651858.CD003018.pub3

197. Luo Y, Weibman D, Halperin JM, Li X (2019) A review of heterogeneity in attention deficit/hyperactivity disorder (ADHD). Front Hum Neurosci 13(42):1-12. https://doi.org/10.3389/fnhum.2019.00042

198. Ly V, Bottelier M, Hoekstra PJ, Arias Vasquez A Buitelaar JK, Rommelse NN (2017) Elimination diets' efficacy and mechanisms in attention deficit hyperactivity disorder and autism spectrum disorder. EurChild Adolesc Psychiatry 26(9):1067-1079. https://doi.org/10.1007/s00787-017-0959-1

199. M. Döpfner, J. Plück, C. Kinnen, and für die Arbeitsgruppe Deutsche Child Behavior Checklist. Deutsche Schulalter-Formen der Child Behavior Check-list von Thomas M. Achenbach - deutsche Schulalter Formen Elternfragebogen über das Verhalten von Kindern und Jugendlichen (CBCL/6$18 \mathrm{R})$, Lehrerfragebogen über das Verhalten von Kindern und Jugendlichen (TRF/6-18R), Fragebogen für Jugendliche (YSR/11-18R). Hogrefe, Göttingen, 2000.

200. Maeir A, Fisher O, Bar-llan RT, Boas N, Bergerl, Landau YE (2014) Effectiveness of cognitive-functional (cog-fun) occupational therapy intervention for young children with attention deficit hyperactivity disorder: a controlled study. Am J Occup Ther 68(3):260-267

201. Mahone EM, Denckla MB (2017) Attentiondeficit/hyperactivity disorder: a historical neuropsychological perspective. J Int Neuropsycho Soc 23(9-10):916-929. https://doi.org/10.1017/ s1355617717000807

202. ManuzzaS, Klein RG, AbikoffH, Moulton JL III (2004) Significance of childhood conduct problems to later development of conduct diorder among children with ADHD: a prospective follow-up study. J Abnorm Child Psychol 32:565-573

203. March JS, Swanson JM, Arnold LE, Hoza B, Conners CK, Hinshaw SP, Hechtman L, Kraemer HC, Greenhill LL, Abikoff HB, Elliott LG, Jensen PS, Newcorn JH, Vitiello B, Severe J, Wells KC, Pelham W (2000) Anxiety as a predictor and outcome variable in the Multimodal Treatment Study of children with ADHD. J Abnorm Child Psychol 28(6):527-541 
204. van der Marel $K$, Bouet $V$, Meerhoff GF, Freret $T$, Boulouard M, Dauphin F, Klomp A, Lucassen PJ, Homberg JR, Dijkhuisen RM, Reneman L (2015) Effects of long-term methylphenidate treatment in adolescent and adult rats on hippocampal shape, functional connectivity and adult neurogenesis. Neuroscience. https://doi.org/10.1016/j. neuroscience.2015.04.044

205. Markowitz JS, Kennerly SP (2017) The clinical pharmacokinetics of amphetamines utilized in the treatment of attention-deficit/hyperactivity disorder. J Child Adolesc Psychopharmacol 27(8):678-689. https://doi.org/10.1089/cap.2017. 0071

206. Martin AJ (2012) Academic buoyancy and academic outcomes: Towards a further understanding of students with attention-deficit/hyperactivity disorder (ADHD), students without ADHD, and academic buoyancy itself. Br J Educ Psychol 84:86-107

207. Martinez-Raga J, Knecht C, Szerman N, Martinez M (2013) Risk of serious cardiovascular problems with medications for attention-deficit hyperactivity disorder. CNSDrugs 27(1):15-30

208. Martínez-Aguayo JC, Arancibia M, Meza-Concha N Bustamante C, Pérez-Bracchiglione J, Madrid E (2017) Brief psychosis induced by methylphenidate in a child with attention deficit disorder: a case report and literature review. Medwave 17(05):e6980-e6980. https://doi.org/10.5867/ medwave.2017.05.6980

209. Matthijssen A-FM, Dietrich A, Margreet Bierens, Kleine Deters $R$, van de Loo-Neus GHH, van den Hoofdakker BJ, Buitelaar JK, Hoekstra PJ (2019) Effects of discontinuing methyl-phenidate on strengths and difficulties, quality of life and parenting stress.J Child Adolesc Psychopharmacol. https://doi.org/10.1089/cap.2019.0147

210. Maughan B, Taylor A, Caspi A, Moffitt TE (2004) Prenatal smoking and early childhood conduct problems: testing genetic and environmental explanations of the association. Arch Gen Psychiatry 61:836-843

211. Max JE, Robin DA, Taylor HG, Fox PT, Lancaster JL, Manes FF, Mathews K, Austerman S(2004)Putamen lesions and the development of attention-deficit/ hyperactivity symptomatology. J Int Neuropsychol Soc 10(7):976-986

212. McLennan JD (2016) Understanding attention deficit hyperactivity disorder as a continuum. Can Fam Physician 62(12):979-982

213. Mill J, Curran S, Richards S, Taylor E, Asherson P (2004) Polymorphisms in the dopamine D5 receptor (DRD5) gene and ADHD. Am J Med Genet Part B Neuropsychiatr Genet 125B(1):38-42

214. Mill J, Richards S, Kinght J, Curran S, Tylor E Asherson P (2004) Haplotype analysis of SNAP25 suggests a role in the aetiology of ADHD. Mol Psychiatry 9(8):801-810

215. Miyazaki C, Momoko Koyama, Ota E, Toshiyuki Swa, Mlunde LB, Amiya RM, Yoshiyuki Tachibana, Kiwako Yamamoto-Hanada, Mori R (2017) Allergic diseases in children with attention deficit hyperactivity disorder: a systematic review and metaanalysis. Bmc Psychiatry 17(120):1-12. https://doi. org/10.1186/s12888-017-1281-7

216. Modesto-Lowe V, Charbonneau V, Farahmand P (2017) Psychotherapy for adolescents with attention-deficit hyperactivity disorder: a pediatrician's guide. Clin Pediatr 56(7):667-674. https://doi.org/ 10.1177/0009922816673308

217. Molina BSG, HinshawSP, Swanson JM, ArnoldLE, Vitiello B, Jensen PS, Epstein JN, Hoza B, Hechtman L, Abikoff HB, Elliott GR, Greenhill LL, Newcorn JH,
Wells TY, Wigal KC, Gibbons RD, Hur K, Houck PR, The MTA Cooperative Group. (2009) The MTA at 8 years: prospective follow-up of children treated for combined-type ADHD in a multisite study. J Am Acad Child Adolesc Psychiatry 48(5):484-500

218. Moll K, Landerl K (2014) SLRT-II Lese- und Rechtschreibtest II Weiterentwicklung des Salzburger Lese- und Rechtschreibtests (SLRT). Hogrefe, Göttingen

219. Moore RY, Bloom FE (1978) Central catecholamine neuron systems: Anatomy and physiology of the dopamine systems. Annu Rev Neurosci 1:129-169

220. Mrug S, Molina BS, Hoza B, Gerdes AC, Hinshaw SP, Hechtman L, Arnold LE (2012) Peer rejection and friendships in children with attentiondeficit/hyperactivity disorder: contributions to long-term outcomes. J Abnorm Child Psychol 40(6):1013-1026

221. Murray AL, Robinson T, Tripp G (2017) Neurocognitive and symptom trajectories of ADHD from childhood to early adolescence. J Dev Behav Pediatr 38(7):465-475. https://doi.org/10.1002/ 14651858.CD003018.pub3

222. Muskens JB, Velders FP, Staal WG (2017) Medical comorbidities in children and adolescents with autism spectrum disorders and attention deficit hyperactivity disorders: a systematic review. Eur Child Adolesc Psychiatry 26(9):1093-1103. https:// doi.org/10.1007/s00787-017-1020-0

223. Myhre $O$, Låg M, Villanger GD, Oftedal B, Ovrevik J, Holme JA, Aase $\mathrm{H}$, Paulsen RE, Bal-Price $A$ Dirven $\mathrm{H}$ (2018) Early life exposure to air pollution particulate matter (PM) as risk factor for attention deficit/hyperactivity disorder (ADHD): Need for novel strategies for mechanisms and causalities. Toxicol Appl Pharmacol 354:196-214. https://doi. org/10.1016/j.taap.2018.03.015

224. National Guideline Centre (UK) (2018) Attention deficit hyperactivity disorder: diagnosis and management. https://www.nice.org.uk/guidance/ ng87.Zugegriffen: 12.5 .2020

225. NICE - National Institute for Health and Care Excellence (2009) The NICE guideline on diagnosis and management of ADHD in children, young people and adults - NICE guideline [NG87], 2018, 2019. https://www.nice.org.uk/guidance/NG87

226. Nickel K, Maier S, Endres D, Joos A, Maier V, Tebartz van Elst L, Zeeck A (2019) Systematic review: Over-lap between eating, autism spectrum, and attention-deficit/hyperactivity disorder. Front Psychiatry 10(708):1-14. https://doi.org/10.3389/ fpsyt.2019.00708

227. Nielsen TM, Pedersen MV Milidou I Glavind J, Henriksen TB (2019) Long-term cognition and behavior in children born at early term gestation: A systematic review. Acta Obstet Gynecol Scand 98(10):1227-1234. https://doi.org/10.1111/aogs. 13644

228. Nigg JT (2006) What causes ADHD? Toward a multipath model for understanding what goes wrong and why. The Guilford PressGuilford, New York

229. Nutt DJ, Fone $K$, Asherson $P$, Bramble $D$, Hill $P$, Matthews K, Morris KA, Santosh P, Sonuga-Barke E, Taylor E, Weiss M, Young S, British Association for Psychopharmacology (2007) Evidence-based guidelines for management of attention-deficit/ hyperactivity disorder in adolescents in transition to adult services and in adults: recommendations from the British Association for Psychopharmacology. J Psychopharmacol 21(1):10-41

230. Ohmann S, Popow C (2014) Unpublished ADHD data
231. Osland ST, Steeves TDL, Pringsheim T (2018) Pharmacological treatment for attention deficit hyperactivity disorder (ADHD) in children with comorbid tic disorders. Cochrane Database Syst Rev. https://doi.org/10.1002/14651858. cd007990.pub3

232. Palazzo Nazar B, Bernardes C, Peachey G, Sergeant J, Mattos P, Treasure J (2016) The risk of eating disorders comorbid with attention-deficit/ hyperactivity disorder: A systematic review and meta-analysis. Int J Eat Disord 49(12):1045-1057. https://doi.org/10.1002/eat.22643

233. Palladino VS, McNeill R, Reif A, Kittel-Schneider S (2019) Genetic risk factors and geneenvironment interactions in adult and childhood attention-deficit/hyperactivity disorder. Psychiatr Genet 29(3):63-78. https://doi.org/10.1097/ypg. 0000000000000220

234. Pappadopulos E, Macintyre JC II, Crismon ML, Findling RL, Malone RP, Derivan A, Schooler N, Sikich L, Greenhill L, Schur SB, Felton CJ, Kranzler H, Rube DM, Sverd J, Finnerty M, Ketner S, SiennickSE, Jensen PS (2003) Treatment recommendations for the use of antipsychotics for aggressive youth (TRAAY). Part ii. J Am Acad Child Adolesc Psychiatry 42:145-161. https://doi.org/10.1097/ 01.CHI.0000037018.34553.CA

235. Park JL, Hudec KL, Johnston C (2017) Parenta ADHD symptoms and parenting behaviors: $A$ meta-analytic review. Clin Psychol Rev 56:25-39. https://doi.org/10.1002/14651858.CD003018. pub3

236. Pei-Chen Chang J, Kuan-Pin S, Mondelli V, Pariante CM (2017) Omega-3 polyunsaturated fatty acids in youths with attention deficit hyperactivity disorder: a systematic review and meta-analysis of clinical trials and biological studies. Neuropsychopharmacology 43(3):534-545. https://doi.org/10. 1038/npp.2017.160

237. Pelsser LM, Frankena K, Toorman J, Rodrigues Pereira R (2017) Diet and adhd, reviewing the evidence: A systematic review of meta-analyses of double-blind placebo-controlled trials evaluating the efficacy of diet interventions on the behavior of children with adhd. Plos One 12(1):e169277. https://doi.org/10.1371/journal.pone.0169277

238. Petermann F, Petermann U (2010) HAWIK ${ }^{\circledR}$-IV Hamburg-Wechsler-Intelligenztest für Kinder Bd. 2010. Hogrefe, Göttingen

239. PievskyMA,McGrath RE (2017) Theneurocognitive profile of attention-deficit/hyperactivity disorder: a review of meta-analyses. Arch Clin Neuropsychol 33(2):143-157. https://doi.org/10.1093/arclin/ acx055

240. Plattner B, The SS, Kraemer HC, Williams RP, Bauer SM, Kindler J, Feucht M, Friedrich $\mathrm{MH}$, Steiner H (2007) Suicidality, psychopathology, and gender in incarcerated adolescents in Austria.JClin Psychiatry60(10):1593-1600

241. Pliszka S (1989) Effect of anxiety on cognition, behavior, and stimulant response in ADHD. J Am Acad Child Adolesc Psychiatry 28(6):882-887

242. Pliszka S (1998) Comorbidity of attention-deficit/ hyperactivity disorder with psychiatric disorder: An overview.J Clin Psychiatry31(2):50-58

243. Pliszka S (2007) Practice parameter for the assessment and treatment of children and adolescents with attention-deficit/hyperactivity disorder. J Am Acad Child Adolesc Psychiatry 46(7):894-921. https://doi.org/10.1097/chi.0b013e318054e724

244. Pliszka SR (2007) Pharmacologic treatment of attention-deficit/hyperactivity disorder: efficacy, safety and mechanisms of action. Neuropsychol 
Rev 17(1):61-72. https://doi.org/10.1007/s11065006-9017-3

245. Plück J, Wieczorrek E, Metternich TW, Döpfner M (2006) Präventionsprogramm für Expansives Problemverhalten. Therapeutische Praxis, Bd. 36. Hogrefe, Göttingen

246. Posner J, Polanczyk GV, Sonuga-Barke E (2020) Attention-deficit hyperactivity disorder. Lancet 395(10222):450-462. https://doi.org/10.1016/ s0140-6736(19)33004-1

247. Pozzi M, Carnovale C, Peeters Gentili GGAMM, Antoniazzi S, Radice S, Clementi E, Nobile M (2018) Adverse drug events related to mood and emotion in paediatric patients $t$ treated for ADHD: A metaanalysis. J Affect Disord 238:161-178. https://doi. org/10.1016/j.jad.2018.05.021

248. Pretus C, Ramos-Quiroga JA, Richarte V, Corrales M, Picado M, Carmona S, Vilarroya Ó (2017) Time and psychostimulants: Opposing long-term structural effects in the adult ADHD brain. a longitudinal MR study. Eur Neuropsychopharmacol 27(12):1238-1247. https://doi.org/10.1016/j. euroneuro.2017.10.035

249. Pringsheim T, Steeves T (2011) Pharmacological treatment for Attention Deficit Hyperactivity Disorder (ADHD) in children with comorbid tic disorders. Cochrane Database Syst Rev. https://doi. org/10.1002/14651858.CD007990.pub2

250. Procyshyn RM, Su J, Elbe D, Liu AY, Panenka WJ, Davidson J, Honer WG, Barr AM (2014) Prevalence and patterns of antipsychotic use in youth at the time of admission and discharge from an inpatient psychiatric facility. J Clin Psychopharmacol 34(1):17-22

251. Punja S, Shamseer L, Hartling L, Urichuk L, Vandermeer B, Nikles J, Vohra S (2016) Amphetamines for attention deficit hyperactivity disorder (ADHD) in children and adolescents. Cochrane Database Syst Rev. https://doi.org/10.1002/14651858. cd009996.pub2

252. Qin Xiang Ng, Yih Xian Ho C, Hwei Wuen C, Zheng Jie BY, Yeo W-S (2017) Managing childhood and adolescent attention-deficit/hyperactivity disorder (ADHD) with exercise: a systematic review. Complement Ther Med 34:123-128. https://doi. org/10.1016/j.ctim.2017.08.018

253. Quian Q, Wang Y, Zhou R, Yang L, Faraone SV (2004) Family-based and case-control association studies of DRD4 and DAT1 polymorphisms in Chinese attention deficit hyperactivity disorder patients suggest long repeats contribute to genetic risk for the disorder. Am J Med Genet 128B:84-89

254. Ramos Olazagasti MA, Klein RG, Mannuzza S, Roizen Belsky E, Hutchison JA, Lashua-Shriftman EC, Castellanos FX (2013) Does childhood attentiondeficit/hyperactivity disorder predict risk-taking and medical illnesses in adulthood? J Am Acad Child Adolesc Psychiatry 52(2):153-162

255. Razoki B (2018) Neurofeedback versus psychostimulants in the treatment of children and adolescents with attention-deficit/hyperactivity disorder: a systematic review. NDT 14:2905-2913. https://doi.org/10.2147/ndt.s178839

256. Reed VA, Buitelaar JK, Anand E, Day KA, Treuer T, Upadhyaya HP, Coghill DR, Kryzhanovskaya LA, Savill NC (2016) The safety of atomoxetine for the treatment of children and adolescents with attention-deficit/hyperactivity disorder: A comprehensive review of over a decade of research. CNS Drugs 30(7):603-628. https://doi. org/10.1007/s40263-016-0349-0

257. ReevesG, AnthonyB (2009) Multimodal treatments versus pharmacotherapy alone in children with psychiatric disorders: implications of access, effectiveness, and contextual treatment. Paediatr Drugs 11(3):165-169

258. Regnart J, Truter I, Meyer A (2017) Critical exploration of co-occurring attention-deficit/ hyperactivity disorder, mood disorder and substance use disorder. Expert Rev Pharmacoecon Outcomes Res 17(3):275-282. https://doi.org/10. 1080/14737167.2017.1351878

259. Reimherr FW, Marchant BK, Gift TE, Steans TA Wender PH (2015) Types of adult attentiondeficit hyperactivity disorder (ADHD): baseline characteristics, initial response, and long-term response to treatment with methylphenidate. Atten Deficit Hyperact Disord 7(2):115-128. https://doi.org/10.1007/s12402-015-0176-z

260. RetzW, Retz-Junginger P, Thome J, Rösler M (2011) Pharmacological treatment of adult ADHD in Europe. World J Biol Psychiatry 12(S1):89-94

261. Richardson E, Seibert T, Uli NK (2017) Growth perturbations from stimulant medications and inhaled corticosteroids. Transl Pediatr 6(4):237-247. https://doi.org/10.21037/tp.2017.09.14

262. Richardson M, Moore DA, Gwernan-Jones $R$, Thompson-Coon J, Ukoumunne O, Rogers $M$, Whear R, Newlove-Delgado TV, Logan S, Morris C, Taylor E, Cooper P, Stein K, Garside R, Ford TJ (2015) Non-pharmacological interventions for attentiondeficit/hyperactivity disorder (ADHD) delivered in school settings: systematic reviews of quantitative and qualitative research. Health Technol Assess 19(45):1-470

263. Roberts W, Mills R, Barkley RA (2015) Primary symptoms, diagnostic criteria, subtyping, and prevalence of ADHD. In: Barkley RA, Barkley RA (Hrsg) Attention deficit hyperactivity disorder. A handbook for diagnosis and treatment, 4 . Aufl. Guilford, New York, S51-80

264. Rogers CE, Lean RE, Wheelock MD, Smyser CD (2018) Aberrant structural and functional connectivity and neurodevelopmental impairment in preterm children. J Neurodevelop Disord. https:// doi.org/10.1186/s11689-018-9253-x

265. Rommelse N, van der Kruijs M, Damhuis J, Hoek I, Smeets S, Antshel KM, Hoogeveen L, Faraone SV (2016) An evidenced-based perspective on the validity of attention-deficit/hyperactivity disorder in the context of high intelligence. Neurosci Biobehav Rev 71:21-47. https://doi.org/10.1016/j. neubiorev.2016.08.032

266. Roth RM, Saykin AJ (2004) Executive dysfunction in attention-deficit/hyperactivity disorder: cognitive and neuroimaging findings. Psychiatr Clin North Am 27(1):83-96

267. Rubia K (2018) Cognitive neuroscience of Attention Deficit Hyperactivity Disorder (ADHD) and its clinical translation. Front Hum Neurosci 12(100):1-23. https://doi.org/10.3389/fnhum.2018.00100

268. Ruediger Kissgen, Franke S (2016) An attachment research perspective on ADHD. Neuropsychiatrie 30(2):63-68. https://doi.org/10.1007/s40211 016-0182-1

269. Ruiz-Goikoetxea M, Cortese S, Aznarez-Sanado M, Magallon S, Alvarez Zallo N, Luis EO, de CastroManglano P, Soutullo C, Arrondo G (2018) Risk of unintentional injuries in children and adolescents with ADHD and the impact of ADHD medications: A systematic review and meta-analysis. Neurosci Biobehav Rev 84:63-71. https://doi.org/10.1016/j. neubiorev.2017.11.007

270. Russell AE, Ford T, Williams R, Russell G (2015) The association between socioeconomic disadvantage and attention deficit/hyperactivity disorder (ADHD): A systematic review. Child Psychiatry
Hum Dev 47(3):440-458. https://doi.org/10.1007/ s10578-015-0578-3

271. Safren SA, Otto MW, Sprich S, Winett CL, Wilens TE, Biederman J (2005) Cognitive-behavioral therapy for adhd in medication-treated adults with continued symptoms. Behav Res Ther 43(7):831-842

272. Sagvolden T, Espen Borgå Johansen HA, Russell VA (2005) A dynamic developmental theory of attention-deficit / hyperactivity disorder (AD$\mathrm{HD}$ ) predominantly hyperactive/impulsive and combined subtypes. Behav Brain Sci 28:397-468. https://doi.org/10.1017/S0140525X05430071

273. Sanders MR (1999) Triple P-Positive Parenting Program: Towards an empirically validated multilevel parenting and family support strategy for the prevention of behavior and emotional problems in children. Clin Child Fam Psychol Rev 2(2):71-90. https://doi.org/10.1023/a:1021843613840

274. Sanders M, Turner KMT, Markle-Dadds C (2009) Das Triple-P Elternarbeitsbuch. Verlag für Psychotherapie, Münster

275. Sarver DE, McCart MR, Sheidow AJ, Letourneau EJ (2014) ADHD and risky sexual behavior in adolescents: conduct problems and substance use as mediators of risk. J Child Psychol Psychiatry Allied Discip 55(12):1345-1353. https://doi.org/ 10.1111/jcpp.12249

276. Sasser T, Schoenfelder EN, Stein MA (2017) Targeting functional impairments in the treatment of children and adolescents with ADHD. Cns Drugs 31(2):97-107. https://doi.org/10.1007/s40263016-0400-1

277. Sawaguch T, Matsumura M, Kubota K (1990) Catecholaminergic effects on neuronal activity related to a delayed response task in monkey prefrontal cortex.J Neurophysiol 63:1385-1400

278. Scarpelli S, Maurizio Gorgoni, D’Atri A, Flaminia R, De Gennaro L (2019) Advances in understanding the relationship between sleep and attention deficit-hyperactivity disorder (ADHD). J Clin Med 8(10):1737.https://doi.org/10.3390/jcm8101737

279. van der Schans J, Ciçek R, de Vries TWJ, Hak E, Hoekstra PJ (2017) Association of atopic diseases and attention-deficit/hyperactivity disorder: a systematic review and meta-analyses. Neurosci Biobehav Rev 74:139-148. https://doi.org/10. 1016/j.neubiorev.2017.01.011

280. Schatz AM, Ballantyne AO, Trauner DA (2001) Sensitivity and specificity of a computerized test of attention in the diagnosis of attention-deficit/ hyperactivity disorder. Assessment 8:357-365

281. Schellig D Corsi block tapping test. https:// www.schuhfried.com/de/wiener-testsystem/. Zugegriffen: 12.5 .2020

282. Schmiedeler S (2015) Achtsamkeitsbasierte Therapieverfahren bei der Aufmerksamkeitsdefizit-/ Hyperaktivitätsstörung (ADHS) [mindfulness-based intervention in Attention-Deficit-/Hyperactivity Disorder (ADHD). Z Kinder Jugendpsychiatr Psychother 43(2):123-131. https://doi.org/10.1024/ 1422-4917/a000341

283. SchultzW, Apicella P, Ljungberg T (1993) Responses of monkey dopamine neurons to reward and conditioned stimuli during successive steps of learning a delayed response task. J Neurosci 13:900-913

284. Schur SB, Sikich L, Findling RL, Malone RP, Crismon ML, Derivan A, Macintyre JC II, Pappadopulos E, Greenhill L, Schooler N, van Orden K, Jensen PS (2003) Treatment recommendations for the use of antipsychotics for aggressive youth (TRAAY). Part ii. A review. J Am Acad Child Adolesc Psychiatry 43(2):132-144. https://doi.org/10. 1097/01.CHI.0000037017.34553.2E 
285. Schwab U (2014) Ressourcen orientierte Wahrnehmung von Kindern mit ADHS [Resource oriented perception of children with ADHD]. Master's thesis, Master Course Public Health, Bd. 6. Medical University of Vienna, Vienna

286. Schwartz S, Correll CU (2014) Efficacy and safety of atomoxetine in children and adolescents with attention-deficit/hyperactivity disorder: Results from a comprehensive meta-analysis and metaregression. J Am Acad Child Adolesc Psychiatry 53(2):174-187

287. Seitz W, Rausche A (2004) PFK 9-14 Persönlichkeitsfragebogen für Kinder zwischen 9 und 14 Jahren. Hogrefe, Göttingen

288. Serati M, Barkin JL, Orsenigo G, Altamura AC, Buoli M (2017) Research review: the role of obstetric and neonatal complications in childhood attention deficit and hyperactivity disorder-a systematic review. J Child Psychol Psychiatry 58(12):1290-1300. https://doi.org/10. 1111/jcpp.12779

289. Sevecke K, Battel S, Dittmann R, Lehmkuhl G, Döpfner M (2005) Wirksamkeit von Atomoxetin bei Kindern, Jugendlichen und Erwachsenen mit ADHS. Eine systematische übersicht. [efficacy of atomoxetine in children and adolescents with ADHD. A systematic overview]. Nervenarzt 77:294308

290. Shafiq S, Pringsheim T (2018) Using antipsychotics for behavioral problems in children. Expert Opin Pharmacother 19(13):1475-1488. https://doi.org/ 10.1080/14656566.2018.1509069

291. Shahrokh A, Sadeghi-Bazargani H, Nazari S, Ranjbar F, Abdi S (2016) Attention deficit/hyperactivity disorder and risk of injuries: a systematic review and meta-analysis. J Inj Violence Res 9(2):95-105. https://doi.org/10.5249/jivr.v9i2.858

292. Shim SH, Yoon HJ, Bak J, Hahn SW, Kim YK (2016) Clinical and neurobiological factors in the management of treatment refractory attentiondeficit hyperactivity disorder. Prog Neuropsychopharmacol Biol Psychiatry 70:237-244. https://doi. org/10.1016/j.pnpbp.2016.04.007

293. Shin MS, Park SY, Park SR, Seol SH, Kwon JS (2006) Clinical and empirical applications of the Rey-Osterrieth Complex Figure Test. Nat Protoc 1(2):892-899

294. Shinaver CS, Entwistle PC, Söderqvist S (2014) Cogmed WM training: reviewing the reviews. App Neuropsychol Child 3(3):163-172. https://doi.org/ 10.1080/21622965.2013.875314

295. Shula Parush, Sohmer H, Steinberg A, Kaitz M (2008) Somatosensory functioning in children with attention deficit hyperactivity disorder. Dev Med Child Neurol 39(7):464-468. https://doi.org/ 10.1111/j.1469-8749.1997.tb07466.x

296. Simkin DR, Thatcher RW, Lubar J (2014) Quantitative EEG and neuro-feedback in children and adolescents: anxiety disorders, depressive disorders, comorbid addiction and attention-deficit/ hyperactivity disorder, and brain injury. Child Adolesc Psychiatr Clin N Am 23(3):427-464

297. Singh I (2008) Beyond polemics: science and ethics of ADHD. Nat Rev Neurosci 9:957-964

298. Smith TF, Schmidt-Kastner R, McGeary JE, Kaczorowski JA, Knopik VS (2016) Pre- and perinatal ischemia-hypoxia, the ischemia-hypoxia response pathway, and ADHD risk. Behav Genet 46(3):467-477. https://doi.org/10.1007/s10519016-9784-4

299. Sonuga-Barke EJS (2005) Causal models of attention-deficit/hyperactivity disorder: from common simple deficits to multiple developmental pathways. Biol Psychiatry 57:1231-1238
300. Sonuga-Barke EJS, Halperin JM (2010) Developmental phenotypes and causal pathways in attention deficit/hyperactivity disorder: potential targets for early intervention? J Child Psychol Psychiatry 51(4):368-389. https://doi.org/10. 1111/j.1469-7610.2009.02195.x

301. Sonuga-Barke EJ, Bitsakou P, Thompson M (2010) Beyond the dual pathway model: evidence for the dissociation of timing, inhibitory, and delay-related impairments in attention-deficit/ hyperactivity disorder. J Am Acad Child Adolesc Psychiatry 49:345-355

302. Sonuga-Barke EJS, Brandeis D, Cortese S, Daley D, Ferrin M, Holtmann M, Stevenson J, Danckaerts M, van der Oord S, Döpfner M, Dittmann RW, Simonoff E, Zuddas A, Banaschewski T, Buitelaar J, Coghill D, Hollis C, Konofal E, Lecendreux M, Wong ICK, Sergeant J, European ADHD Guidelines Group. (2013) Nonpharmacological interventions for ADHD: Systematic review and meta-analyses of randomized controlled trials of dietary and psychological treatments. Am J Psychiatry 170(3):275-289

303. Soorani-Lunsing I, Woltil HA, Hadders-Algra M (2001) Are moderate degrees of hyperbilirubinemia in healthy term neonates really safe for the brain? Pediatr Res 50:701-705

304. Soutullo C, Banaschewski T, Lecendreux $M$, Johnson M, Zuddas A, Anderson C, Civil R, Higgins N, Bloomfield R, Squires LA, Coghill DR (2013) A post hoc comparison of the effects of lisdexamfetamine dimesylate and osmotic-release oral system methylphenidate on symptoms of attention-deficit hyperactivity disorder in children and adolescents. CNS Drugs 27(9):743-751

305. Spencer-Smith M, Klingberg T (2015) Benefits of a working memory training program for inattention in daily life: a systematic review and meta-analysis. Plos One 10(3):e119522. https:// doi.org/10.1371/journal.pone.0119522

306. Stern A, Pollak Y, Bonne O, Elad M, Maeir A (2016) The relationship between executive functions and quality of life in adults with ADHD. J Atten Disord 21(4):323-330. https://doi.org/10.1177/ 1087054713504133

307. Stevenson J, Buitelaar J, Cortese S, Ferrin M, Konofal E, Lecendreux M, Simonoff E, Wong ICK Sonuga-Barke E, European ADHD Guidelines Group (2014) Research review: the role of diet in the treatment of attention-deficit/hyperactivity disorder-an appraisal of the evidence on efficacy and recommendations on the design of future studies. J Child Psychol Psychiatry 55(5):416-427. https://doi.org/10.1002/14651858.CD003018. pub3

308. Stiensmeier-Pelster J, Braune-Krickau M, Schürmann M, Duda K (2014) DIKJ Depressionsinventar für Kinder und Jugendliche. Hogrefe, Göttingen

309. Storebø OJ, Pedersen N, Ramstad E, Kielsholm ML, Nielsen SS, Krogh HB, Moreira-Maia CR, Magnusson FL, Holmskov M, Gerner T, Skoog M, Rosendal S, Groth C, Gillies D, Buch Rasmussen K, Gauci D, Zwi M, Kirubakaran R, Håkonsen SJ, Aagaard L, Simonsen E, Gluud C (2018) Methylphenidate for attention deficit hyperactivity disorder (adhd) in children and adolescents-assessment of adverse events in non-randomised studies. Cochrane Database Syst Rev 5(Cd012069):1-544. https:// doi.org/10.1002/14651858.CD012069.pub2

310. van Stralen J (2016) Emotional dysregulation in children with attention-deficit/hyperactivity disorder. Atten Deficit Hyperact Disord 8(4):175-187. https://doi.org/10.1007/s12402-016-0199-0
311. Sudre G, Mangalmurti A, Shaw P (2018) Growing out of attention deficit hyperactivity disorder: Insights from the 'remitted' brain. Neurosci Biobehav Rev 94:198-209. https://doi.org/10. 1016/j.neubiorev.2018.08.010

312. Suhr JA, Berry DTR (2017) The importance of assessing for validity of symptom report and performance in attention deficit/hyperactivity disorder (ADHD): Introduction to the special section on noncredible presentation in ADHD. Psychol Assess 29(12):1427-1428. https://doi.org/ $10.1037 /$ pas0000535

313. Swensen AR, Birnbaum HG, Secnik K, Marychenko M, Greenberg P, Claxton A (2003) Attentiondeficit/hyperactivity disorder: increased costs for patients and theirfamilies. J Am Acad Child Adolesc Psychiatry 42(12):1415-1423

314. Tandon M, Pergjika A (2017) Attention deficit hyperactivity disorder in preschool-age children. Child Adolesc Psychiatr Clin N Am 26(3):523-538. https://doi.org/10.1016/j.chc.2017.02.007

315. Taylor EA, Sonuga-Barke EJS (2008) Disorders of attention and activity. In: Rutter's child and adolescent psychiatry. Wiley-Blackwell, Oxford, S 521-542

316. Tellegen PJ, Laros JA (2005) SON-R 5 1/2-17 Nonverbaler Intelligenztest. Hogrefe, Göttingen

317. Tellegen PJ, Laros JA, Petermann F (2007) SON-R 2 1/2 - 7 Non-verbaler Intelligenztest. Hogrefe, Göttingen

318. Test of Variables of Attention (T.O.V.A ${ }^{\circledR}$ Version 8). http://www.tovatest.com. Zugegriffen: 12.5 .2020

319. Thapar A (2018) Discoveries on the genetics of ADHD in the 21st century: New findings and their implications. Maerican J Psychiatry 175:943-950. https://doi.org/10.1176/appi.ajp.2018.18040383

320. The MTA Cooperative Group (1999) A 14-month randomized clinical trial of treatment strategies for attention-deficit/hyperactivity disorder. Arch Gen Psychiatry 56:1073-1086

321. The MTA Cooperative Group. (1999) Moderators and mediators of treatment response for children with attention-deficit/hyperactivity disorder. Arch Gen Psychiatry 56:1088-1096

322. Thomas R, Abell B, Webb HJ, Elbina Avdagic Zimmer-Gembeck MJ (2017) Parent-child interaction therapy: a meta-analysis. Pediatrics 140(3):e20170352. https://doi.org/10.1542/peds. 2017-0352

323. Todd RD, Neuman RJ (2007) Gene-environment interactions in the development of combined type ADHD: evidence for a synapse-based model. Am J Med Genet Part B Neuropsychiatr Genet 144B(8):971-175. https://doi.org/10.1002/ajmg. b.30640

324. Troksa K, Kovacich N, Moro M, Chavez B (2019) Impact of central nervous system stimulant medication use on growth in pediatric populations with attention-deficit/hyperactivity disorder: $A$ review. Pharmacotherapy 39(6):665-676. https:// doi.org/10.1002/phar.2192

325. Tuche O, Lange W (2004) Turm von London, Deutsche Version TL-D. Hogrefe, Göttingen

326. Tung I, Li JJ, Meza Jl, Jezior KL, Kianmahd JS, Hentschel PG, O'Neil PM, Lee SS (2016) Patterns of comorbidity among girls with ADHD: a metaanalysis. Pediatrics 138(4):e20160430-13. https:// doi.org/10.1002/14651858.CD003018.pub3

327. Verlaet AAJ, Maasakkers CM, Hermans N, Savelkoul HFJ (2018) Rationale for dietary antioxidant treatment of adhd. Nutrients 10(4):2072-6643. https://doi.org/10.3390/nu10040405

328. Vermiglio $F$, Lo Presti VP, Moleti $M$, Sidoti $M$, Tortorella G, Scaffidi G, Castagna MG, Mattina F 
Violi MA, Crisà A, Artemisia A, Trimarchi F (2004) Attention deficit and hyperactivity disorders in the offspring of mothers exposed to mildmoderate iodine deficiency: a possible novel iodine deficiency disorder in developed countries. JClinEndocrinol Metab 89(12):6054-6060.https:// doi.org/10.1210/jc.2004-0571

329. Verrotti A, Moavero R, Panzarino G, Di Paolantonio C, Rizzo R, Curatolo P (2017) The challenge of pharmacotherapyinchildren and adolescents with epilepsy-ADHD comorbidity. Clin Drug Investig 38(1):1-8. https://doi.org/10.1007/s40261-0170585- 1

330. Vieira de Melo BB, Trigueiro MJ, Pereira Rodrigues $P$ (2017) Systematic overview of neuroanatomical differences in ADHD: definitive evidence. Dev Neuropsychol 43(1):52-68. https://doi.org/10. 1080/87565641.2017.1414821

331. Villemonteix $T$, De Brito $S A$, Kavec $M$, Balériaux $D$, Metens $T$, Slama $H$, Baijot $S$, Mary $A$, Peigneux P, Massat I (2015) Grey matter volumes in treatment naïve vs. chronically treated children with attention deficit/hyperactivity disorder: a combined approach. Eur Neuropsychopharmacol 25(8):1118-1127. https://doi.org/10.1016/j. euroneuro.2015.04.015

332. Vitria Adisetiyo (2018) Revealing the structural neural circuitry of attention deficit hyperactivity disorder with diffusion MRI: Implications for future diagnosis and treatment. Am J Roentgenol 210(4):731-733. https://doi.org/10.2214/ajr.17. 18983

333. Voeller KKS (2004) Attention-deficit hyperactivity disorder (ADHD). J Child Neurol 19(10):798-814

334. Wagner DJ, McLennan JD (2015) An alternative approach to scoring the MTA-SNAP-IV to guide attention-deficit/hyperactivity disorder medication treatment titration towards symptom remission: a preliminary consideration. J Child Adolesc Psychopharmacol 25(10):749-753. https://doi.org/ 10.1089/cap.2015.0081

335. Wang B, Nanqi Y, Zhou X, Liu J, Lv Z (2017) The association between attention deficit/ hyperactivity disorder and internet addiction: a systematic review and meta-analysis. BMC Psychiatry. https://doi.org/10.1186/s12888-0171408-x

336. Wechlser D, Petermann F, Lipsius M (2011) WPPSIIII Wechsler preschool and primary scale of intelligence. Hogrefe, Göttingen

337. Weiss M, Panagiotopoulos C, Giles L, Gibbins C, Kuzeljevic B, Davidson J, Harrison R (2009) A naturalistic study of predictors and risks of atypical antipsychotic use in an attention-deficit/ hyperactivity disorder clinic. J Child Adolesc Psychopharmacol 19(5):575-582

338. Weissenberger S, Ptacek R, Klicperova-Baker M, Erman A, Schonova K, Raboch J, Goetz M (2017) ADHD, lifestyles and comorbidities: a call for an holistic perspective - from medical to societal intervening factors. Front Psychology. https://doi. org/10.3389/fpsyg.2017.00454

339. Wickens MM, Bangasser DA, Briand LA (2018) Sex differences in psychiatric disease: a focus on the glutamate system. Front Mol Neurosci 11(197):1-12. https://doi.org/10.3389/fnmol. 2018.00197

340. Wigal SB, Gupta S, Greenhill L, Posner M, Lerner K, Steinhoff K, Wigal T, Kapelinski A, Martinez J, Modi NB, Stehli A, Swanson J (2007) Pharmacokinetics of methylphenidate in preschoolers with attention-deficit/hyperactivity disorder. J Child Adolesc Psychopharmaco 17(2):153-164
341. Wilens TE, Biederman J, Mick E, Faraone SV (1997) Attention deficit hyperactivity disorder (ADHD) is associated with early onset substance use disorders. J Nerv Ment Dis 185:475-482

342. Wilens TE, Isenberg BM, Kaminski TA, Lyons RM, Quintero J (2018) Attention-deficit/hyperactivity disorder and transitional aged youth. Curr Psychiatry Rep. https://doi.org/10.1007/s11920018-0968-X

343. Willcutt EG, Doyle AE, Nigg JT, Faraone SV, Pennington BF (2005) Validity of the executive function theory of Attention Deficit/ Hyperactivity Disorder: a meta-analytic review. Biol Psychiatry 57:1336-1346. https://doi.org/10.1002/ 14651858.CD003018.pub3

344. Willcutt EG, Pennington BF, Chhabildas NA, Friedman MC, Alexander J (1999) Psychiatric comorbidity associated with DSM-IV ADHD in a nonreferred sample of twins. J Am Acad Child Adolesc Psychiatry 38(11):1355-1362

345. Williams AE, Giust J, Kronenberger W, Dunn D (2016) Epilepsy and attention-deficit hyperactivity disorder: links, risks, and challenges. NDT 12:287-296. https://doi.org/10.2147/ndt.s81549

346. Williamson D, Johnston C (2015) Gender differences in adults with attention-deficit/ hyperactivity disorder: a narrative review. Clin Psychol Rev 40:15-27. https://doi.org/10.1016/j. cpr.2015.05.005

347. Wilson JJ, Levin FR (2005) Attention-deficit/ hyperactivity disorder and early-onset substance use disorders. J Child Adolesc Psychopharmacol 15(5):751-763. https://doi.org/10.1089/cap.2005. 15.751

348. Wodka EL, Mahone EM, Blankner JG, Larson JCG, Fotedar S, Denckla MB, Mostofsky SH (2007) Evidence that response inhibition is a primary deficit in ADHD. J Clin Exp Neuropsychol 29(4):345-356

349. Wong ICK, Banaschewski T, Buitelaar J, Cortese $S$, Dopfner M, Simonoff E, Coghill D (2019) Emerging challenges in pharmacotherapy research on attention-deficit hyperactivity disorder-outcome measures beyond symptom control and clinical trials. Lancet Psychiatry 6(6):528-537. https://doi. org/10.1016/s2215-0366(19)30096-3

350. World Health Organization (2019) ICD-11 for mortality and morbidity statistics (Version: 04/2019). https://icd.who.int/browse11/l-m/en. Zugegriffen: 12.5 .2020

351. Wu EQ, Hodgkins P, Ben-Hamadi R, Setyawan J, Xie J, Sikirica V, Du EX, Yan SY, Erder MH (2012) Cost effectiveness of pharmaco-therapies for attention-deficit hyperactivity disorder: a systematic literature review. Cns Drugs 26(7):581-600

352. Young S, Moss D, Sedgwick O, Fridman M, Hodgkins P (2014) A meta-analysis of the prevalence of attention deficit hyperactivity disorder in incarcerated populations. Psychol Med 45(2):247-258. https://doi.org/10.1017/ s0033291714000762

353. Yule AM, Wilens TE, Martelon MK, Simon A, Biederman J (2013) Does exposure to parental substance use disorders increase substance use disorder risk in offspring? A 5 -year follow-up study. Am J Addict 22(5):460-465

354. Zelazo PD, Mueller U (2002) The Blackwell Handbook of Childhood Cognitive Development, chapter Executive function in typical and atypical development. Blackwell, Malden, S445-469

355. Zhao Y, Liang X, Zhu F, Wen Y, Xu J, Jian Y, Ding M, Cheng B, Ma M, Zhang L, Cheng S, Wu C, Wang S, Wang X, Ning Y, Guo X, Zhang F (2018) A large-scale integrative analysis of GWAS and common meQTLs across whole life course identifies genes, pathways and tissue/cell types for three major psychiatric disorders. Neurosci Biobehav Rev 95:347-352. https://doi.org/10.1016/j.neubiorev.2018.10.005

356. Zimmermann P, Fimm B (2012) TAP 2.3.1 Testbatterie zur Aufmerksamkeitsprüfung. https://www. psytest.de/index.php?page=TAP-2-2\&hl=de_DE. Zugegriffen: 12.5 .2020

357. Zimmermann P, Gondan M, Fimm B (2002) Testbatterie zur Aufmerksamkeitsprüfung für Kinder. https://www.psytest.de/index.php? page=KiTAP\&hl=de_DE.Zugegriffen: 12.5.2020

358. Zulauf MW, Schweiter M, von Aster M, Weinhold M Horn R (2005) ZAREKI-R Testverfahren zur Dyskalkulie bei Kindern - revidierte Fassung. Hogrefe, Göttingen

359. Zwi M, Jones H, Thorgaard C, York A, Dennis JA (2011) Parent training interventions for Attention Deficit Hyperactivity Disorder (ADHD) in children aged 5 to 18 years. Cochrane Database Syst Rev. https://doi.org/10.1002/14651858.CD003018. pub3

360. Østergaard SD, Larsen JT, Soren Dalsgaard, Wilens TE, Mortensen PB, Agerbo E, Mors O, Petersen $L$ (2016) Predicting ADHD by assessment of Rutter's Indicators of Adversity in Infancy. Plos One 11(6):e157352. https://doi.org/10.1371/ journal.pone.0157352

Hinweis des Verlags. Der Verlag bleibt in Hinblick auf geografische Zuordnungen und Gebietsbezeichnungen in veröffentlichten Karten und Institutsadressen neutral. 